\title{
The relative contributions of advection and isopycnal and diapycnal mixing below the subtropical salinity maximum
}

\author{
Eva Bauer* ${ }^{*}$ and Gerold SIEdler*
}

(Received 17 August 1987; in revised form 16 December 1987; accepted 28 December 1987)

\begin{abstract}
The spatial distribution of the subtropical salinity maximum is identified using historical and recent data from the eastern North Atlantic. In the regions with high frequency of occurrence of the salinity maximum, the relative contributions of advection, eddy diffusion and double diffusion to the salt balance below the maximum salinity layer are determined. MCDougall's (1984, Journal of Physical Oceanography, 14, 1577-1589) salt balance equation for neutral surfaces is used in this analysis. The data base consists of two meridional CTD sections along $33^{\circ}$ and $27^{\circ} \mathrm{W}$ between $10^{\circ}$ and $35^{\circ} \mathrm{N}$, mean temperature-salinity profiles in $5^{\circ} \times 5^{\circ}$ squares presented by EMERY and DEWAR (1982), and mean velocity profiles in $3^{\circ} \times 3^{\circ}$ squares evaluated by STRAMMA (1984, Journal of Marine Research, 42, 537-558).

The tropical salinity maximum tongue is found to be quite persistent in its salinity value and its geographic distribution, but less clearly in its vertical or isopycnal position. Double diffusion due to salt-fingering appears to be an important process for the salt balance below the salinity maximum layer. An approximate estimate of the double-diffusive salt flux is obtained. Near the subtropical source region, the double-diffusive salt flux is balanced primarily by isopycnal advection; further to the south it is also balanced by isopycnal eddy diffusion. Maximum doublediffusive fluxes correspond in magnitude to the mean salt flux caused by the excess in evaporation at the surface in the central subtropics. The resulting isopycnal and diapycnal eddy-mixing coefficients derived by a linear inversion technique have the reasonable values of $K_{\mathrm{i}}=(11 \pm 5) \times 10^{2} \mathrm{~m}^{2} \mathrm{~s}^{-1}$ and $K_{\mathrm{d}}=(4 \pm 2) \times 10^{-5} \mathrm{~m}^{2} \mathrm{~s}^{-1}$. Considering the intermittency of the double-diffusive process, limiting values for the mean eddy-mixing coefficients are determined by neglecting the contribution of the double-diffusive salt fluxes. This leads to $K_{\mathrm{i}}=(5 \pm 2) \times 10^{2} \mathrm{~m}^{2} \mathrm{~s}^{-1}$ and $K_{\mathrm{d}}=(5 \pm 1) \times 10^{-5} \mathrm{~m}^{2} \mathrm{~s}^{-1}$ for the isopycnal and diapycnal mixing coefficients, respectively.
\end{abstract}

\section{INTRODUCTION}

THE excess of evaporation over precipitation in the central regions of the subtropical oceans produces dense high-salinity water. After its submersion due to Ekman pumping and convection, this water can be traced in neighbouring areas as a maximum in salinity profiles between the oceanic mixed layer and the main thermocline. Defant (1936) coined the name "subtropical salinity maximum" although he realized that it is found not only in the subtropical source region but also in the tropics. He described its distribution in the North Atlantic and related it to a formation region in the central subtropics and an outflow below the surface layer where the water is carried away by the large-scale circulation in the subtropical gyre and the equatorial currents. From the data base available at the time, he concluded that a belt extending from the Cape Blanc-Cape Verde African coastline to the south-southwest has no salinity maximum; he also noted a

\footnotetext{
* Institut für Meereskunde, Düsternbrooker Weg 20, D 2300 Kiel, F.R.G.

$\dagger$ Present address: Max-Planck-Institut für Meteorologie, Bundesstr. 55, D 2000 Hamburg 13, F.R.G.
} 
poleward boundary of this feature. The belt region seemed to coincide with a corresponding confluence zone.

MONTGOMERY (1938) concluded that the flow of the salinity maximum layer is isentropic and that its source occurs at the intersection of the potential density surfaces with the vertically homogeneous surface layer. He suggested that the observed decrease in salinity on isopycnal surfaces in the zone of the North Equatorial Current is related to the preponderance of lateral over vertical mixing.

WORTHINGTON (1976) discussed the distribution of the salinity maximum using more recent data from the North Atlantic. From a salinity anomaly analysis he determined an equatorward boundary near the Cape Verde Islands. A strong correlation between salinity and oxygen concentrations indicated a rapid convergence in the source region. He concluded from the analysis of two sections from different years that the formation of this salinity maximum water must be strictly dependent upon the trade winds. In an investigation of the thermohaline stratification in the northeastern Carribean Sea, LAMBERT and STURGES (1977) used the name "Subtropical underwater" for the same type of water mass. They concluded that the advected water mass is finally dispersed by the salt-fingering process.

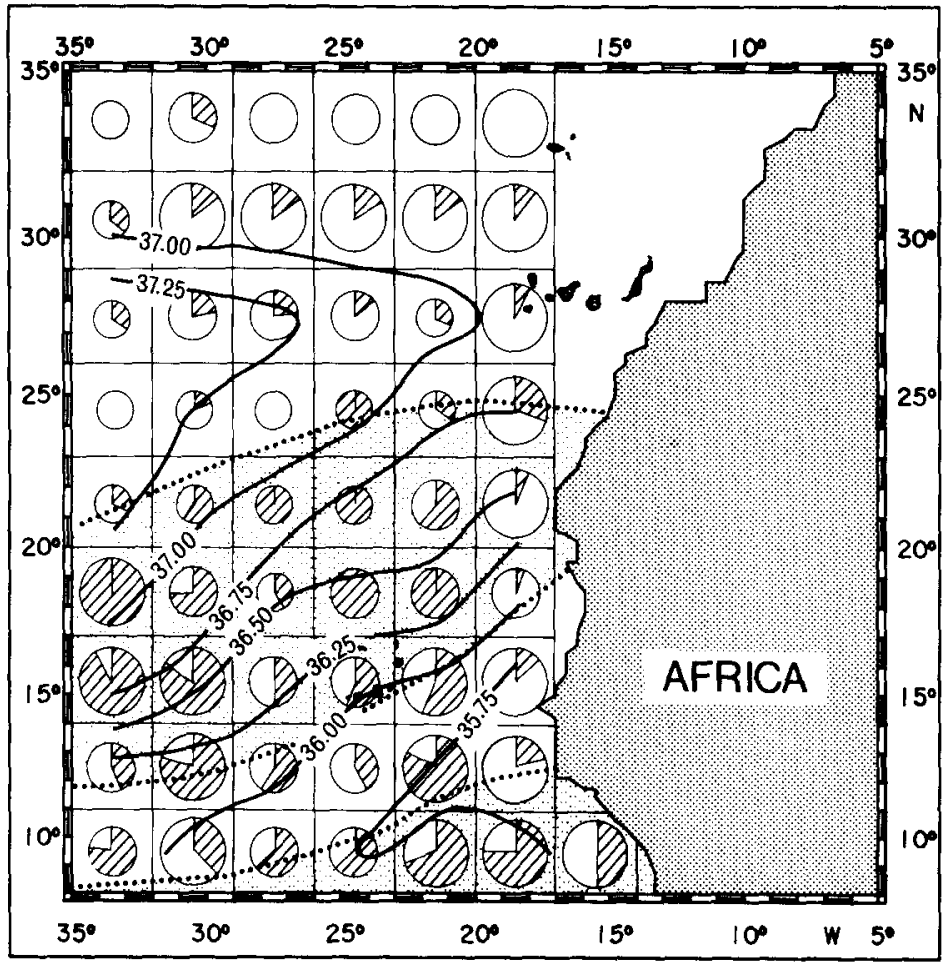

Fig. 1. Frequency of occurrence of the subtropical salinity maximum water derived from historical data. The small, medium, and large circles correspond to the number of stations available in each $3^{\circ} \times 3^{\circ}$ square with classes for $1-7,8-20$ and 21-200, respectively. The fraction of stations with salinity maximum in each square is given by the hatched part in the circle. The isohalines refer to the value at the salinity maximum based on averaged profiles per square, and the dotted regions indicate the salinity maximum areas determined by DEFANT (1936). For details of the data set and data processing see WILLENBRINK (1982). 
Figure 1 presents a recent analysis of the international hydrographic data set from the eastern North Atlantic resulting mainly from Nansen bottle sampling. The mean salinity maximum distribution on the whole corresponds to Defant's and Worthington's results. The frequency of occurrence of a salinity maximum given by the hatched part in the circles of each square, however, indicates less well-defined boundaries between regions with and without salinity maximum water. According to the frequency distributions in Fig. 1, salinity maximum water is occasionally observed north of the source region characterized by the highest surface salinity, but it is also found in the belt off the African coast south of the Cape Verde Islands which is devoid of maxima according to Defant. Examples of salinity, temperature and density profiles from the source and the spreading regions are shown in Fig. 2. Time-series profiles in the Equatorial Counter Current region show a strong temporal variability and fine-structure in the salinity maximum layer (Fig. 3), probably caused by the advection of a spatially varying structure from the west and simultaneous deformation by internal wave motion.
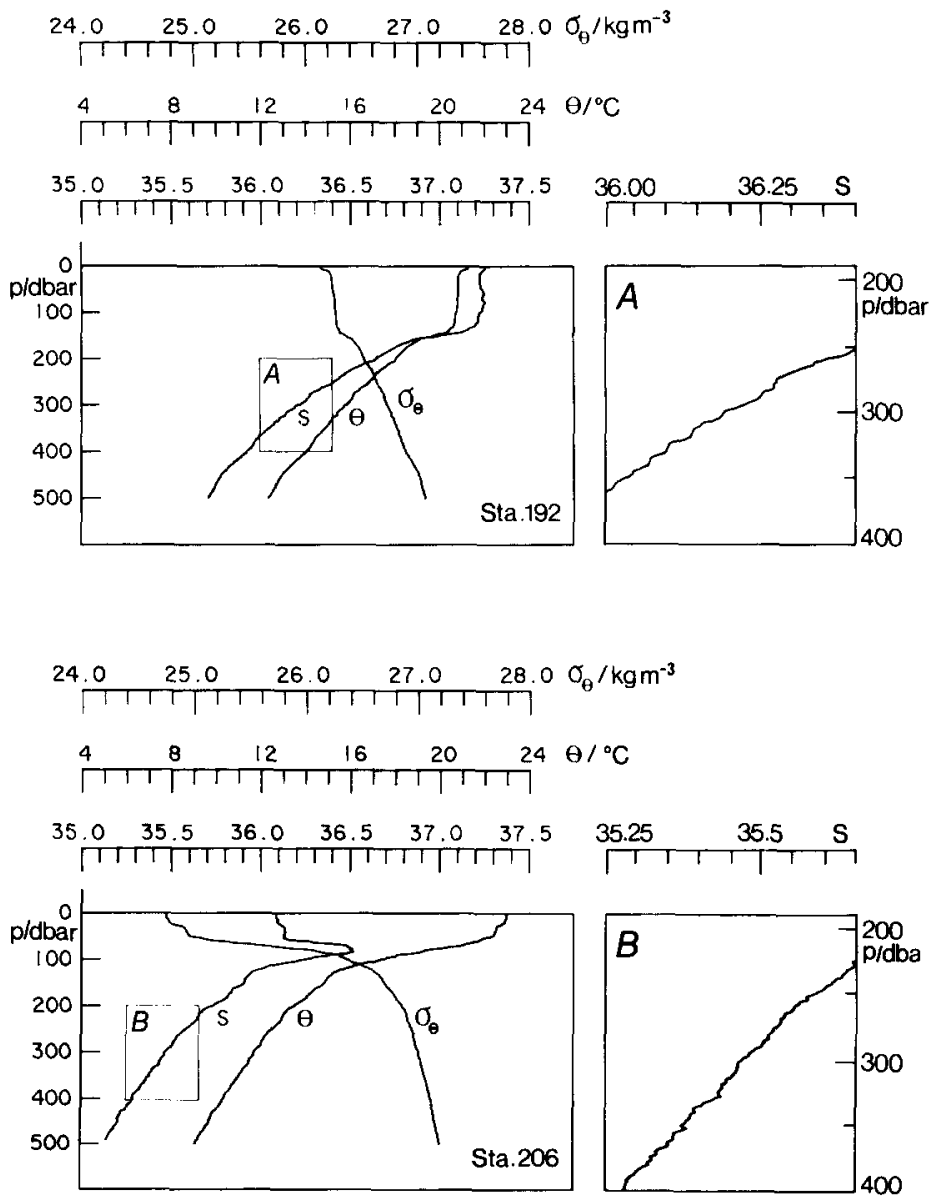

Fig. 2. Salinity $S$, potential temperature $\theta$, and potential density $\sigma_{\theta}$ vs pressure $p$ in the source region at $25^{\circ} \mathrm{N}, 27^{\circ} \mathrm{W}$ (above) and the spreading region at $16.7^{\circ} \mathrm{N}, 27^{\circ} \mathrm{W}$ (below), with haline staircases with expanded scale on the right side. 

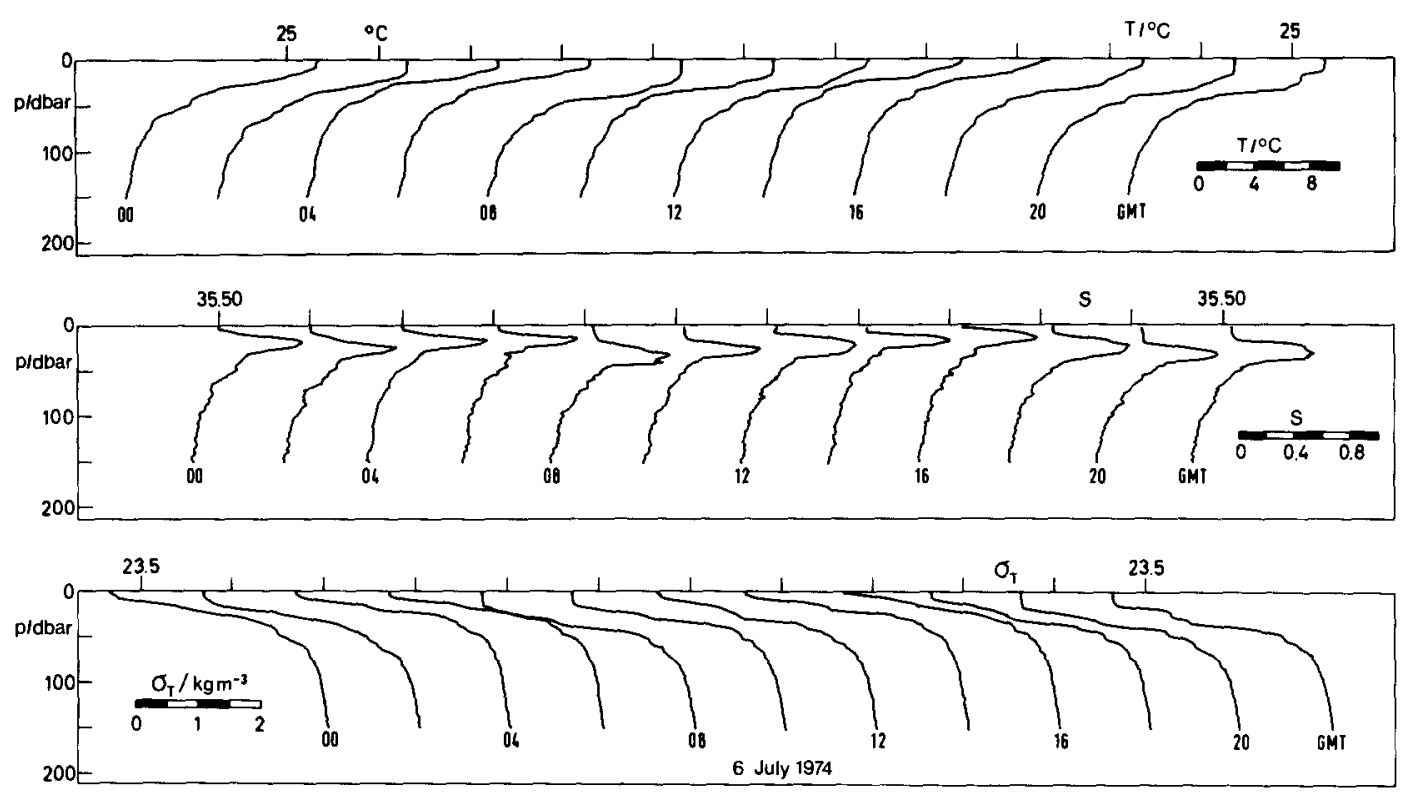

Fig. 3. Time series of temperature $T$, salinity $S$ and density $\sigma_{T}$ vs pressure $p$ in the Equatorial Counter Current region at approx. $8^{\circ} \mathrm{N}, 22^{\circ} \mathrm{W}$ (after PETERS, 1978). The scales are displaced as indicated on the upper line of each box, corresponding to the time interval between individual profiles.

It is an intriguing fact that the salinity maximum seems to persist while it is advected below the surface layer over large distances. The salinity maximum water forms the upper boundary of the North Atlantic Central Water. A direct effect of surface sources and sinks is not to be expected in this depth range. The $\beta$-spiral studies of ARMI and Stommel (1983) as well as tracer models (Thiele et al., 1986) lead to the conclusion that the water mass distribution in the Central Water of this region is dominated by isopycnal advection and isopycnal mixing. On the other hand, SCHMITT (1981) found evidence for cross-isopycnal mixing in the Central Water which can be related to double diffusion. The question is whether this is also the case at the upper Central Water boundary, i.e. below the subtropical salinity maximum where conditions can be favourable for double diffusion.

Thermohaline staircases can frequently be found there (see Fig. 2). The aim of the present study is to check whether double-diffusive fluxes play a significnat role in this depth range and to determine the relative contributions of isopycnal advection, isopycnal and diapycnal diffusion.

\section{MERIDIONAL DISTRIBUTIONS}

Many of the data used here were collected during the F.S. Meteor cruise no. 60 in March/April 1982. Two long meridional CTD sections running along $27^{\circ}$ and $33^{\circ} \mathrm{W}$ covered the latitude range from $35^{\circ}$ to $10^{\circ} \mathrm{N}$ (Fig. 4). Figures 5 and 6 show the meridional distribution of salinity, potential temperature and density in the upper ocean along $33^{\circ}$ and $27^{\circ} \mathrm{W}$, respectively. The source regions are found between $21^{\circ}$ and $27^{\circ} \mathrm{N}$ in the 


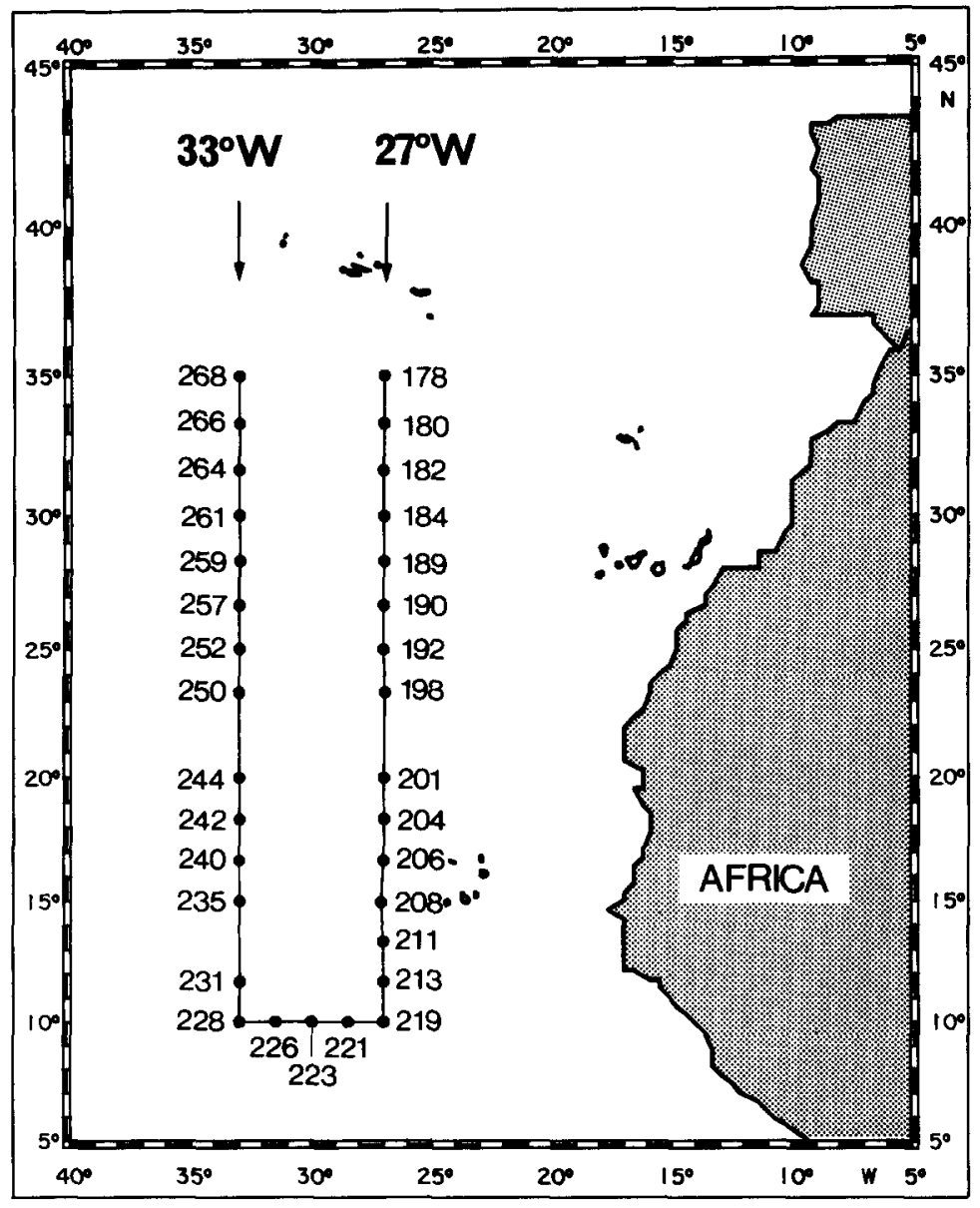

Fig. 4. CTD stations from F.S. Meteor cruise no. 60, 20 March-10 April 1982.

western section and in a narrow region at $25^{\jmath} \mathrm{N}$ in the eastern section, with the isohaline layers reaching down to about $140 \mathrm{~m}$ depth. The salinity maximum layers are documented by a deflection of isohalines at about $100 \mathrm{~m}$ depth towards the south and less well-pronounced at about $120 \mathrm{~m}$ towards the north. A comparison with the temperature and density sections displays a strong influence of salinity on density in the upper layers south of the source region. The overall structure of the density sections corresponds to the baroclinic flow field of the eastern Atlantic subtropical gyre (Fig. 13), with eastward flow components at the northern edge and westward flow components in the southern half of the sections (STRAmma, 1984).

The salinity maximum water seems to follow the corresponding density layer on its way to the south. Plotting salinity vs potential density eliminates particularly internal wave noise. Sections of salinity and temperature vs potential density are shown in Fig. 7 for $33^{\circ} \mathrm{W}$ and Fig. 8 for $27^{\circ} \mathrm{W}$. The salinity maximum water is seen in the curvature of the isohalines in the upper southern part of the salinity section. It appears that the maximum does not everywhere follow isopycnal surfaces. Upward sloping of isohalines towards the 

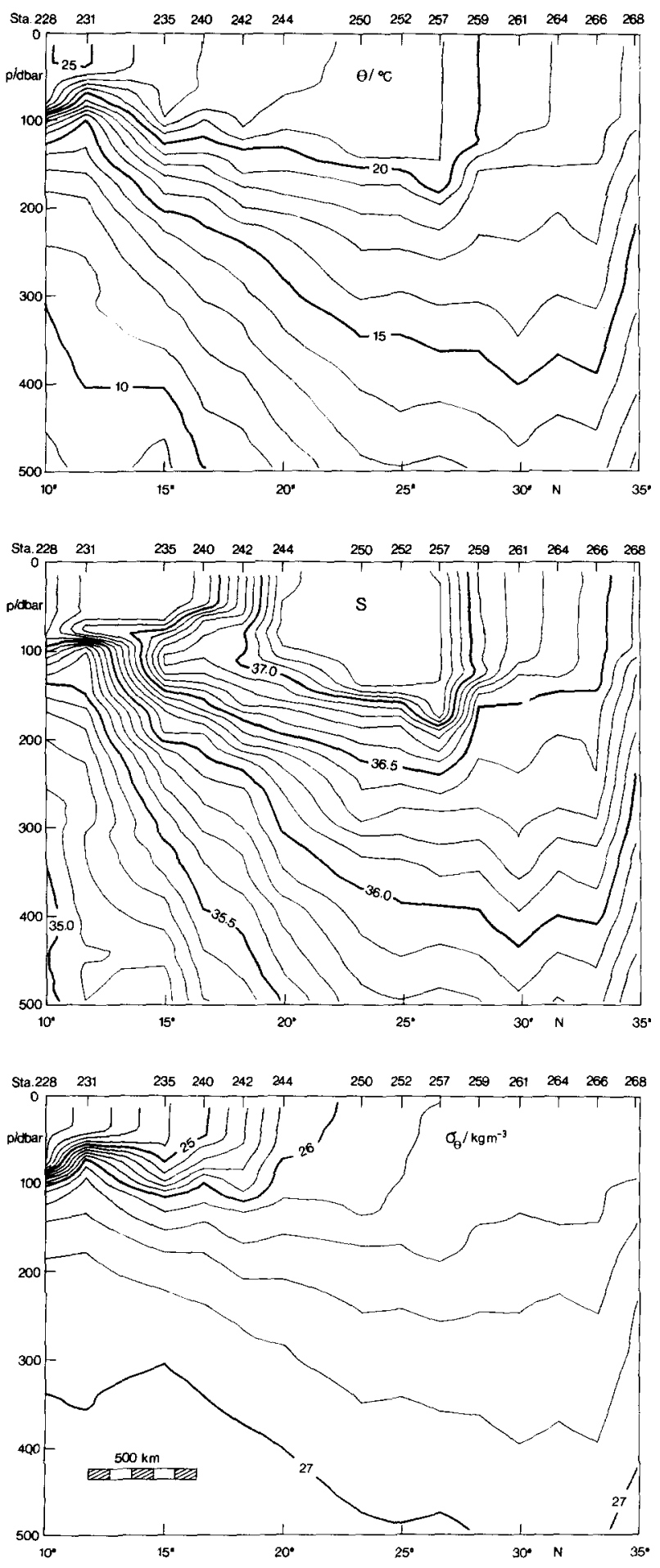

Fig. 5. Sections of potential temperature $\theta$, salinity $S$, and potential density $\sigma_{\theta}$ vs pressure $p$ along $33^{\circ} \mathrm{W}$. For station positions see Fig. 4. 

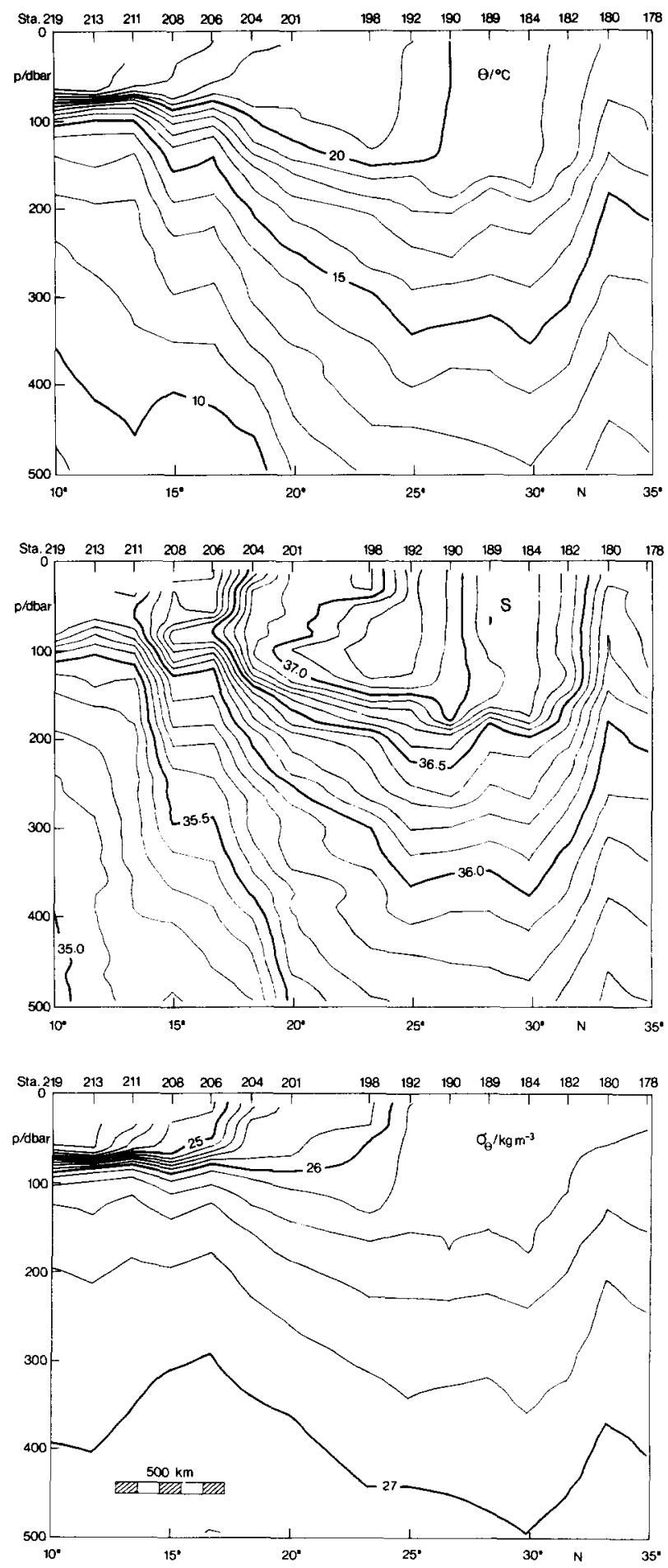

Fig. 6. Sections of potential temperature $\theta$, salinity $S$, and potential density $\sigma_{\theta}$ vs pressure $p$ along $27^{\circ} \mathrm{W}$. For station positions see Fig. 4. 

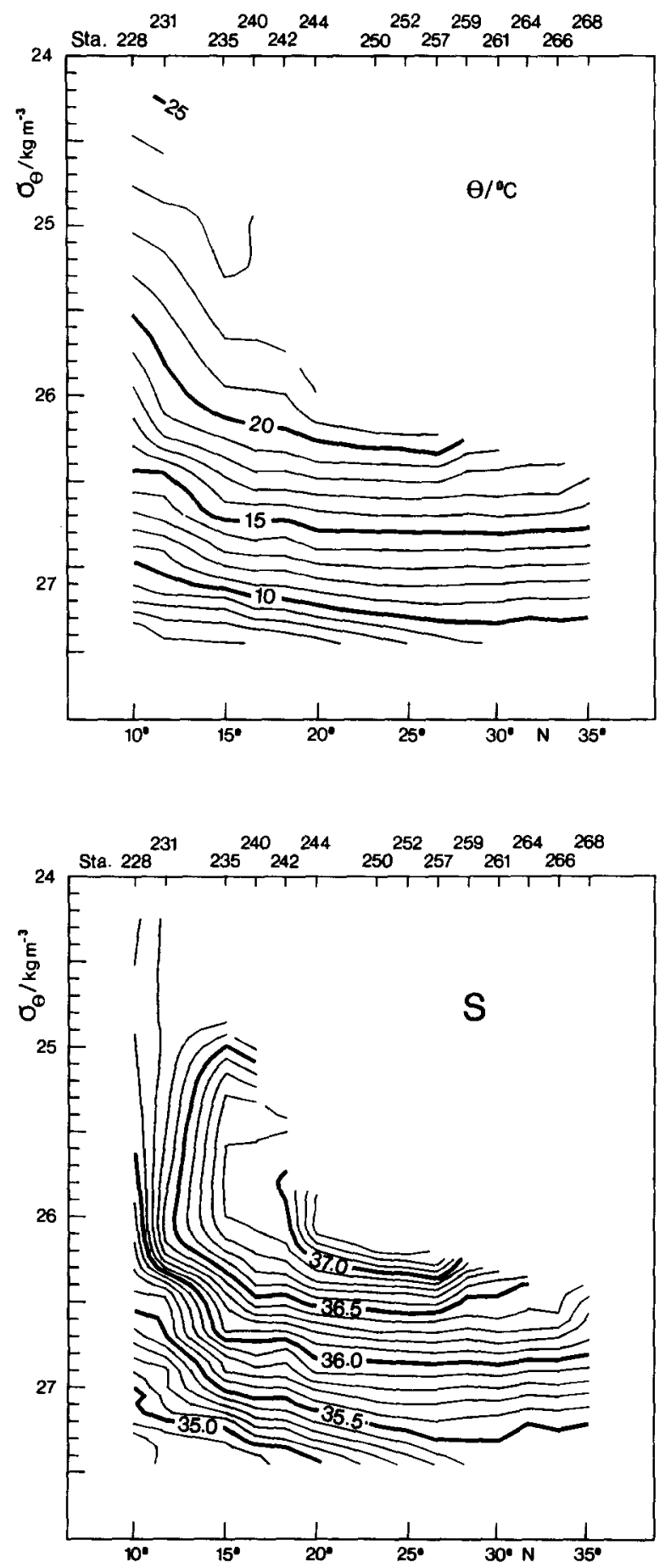

Fig. 7. Sections of potential temperature $\theta$ and salinity $S$ vs potential density $\sigma_{\theta}$ along $33^{\circ} \mathrm{W}$. For station positions see Fig. 4 . 

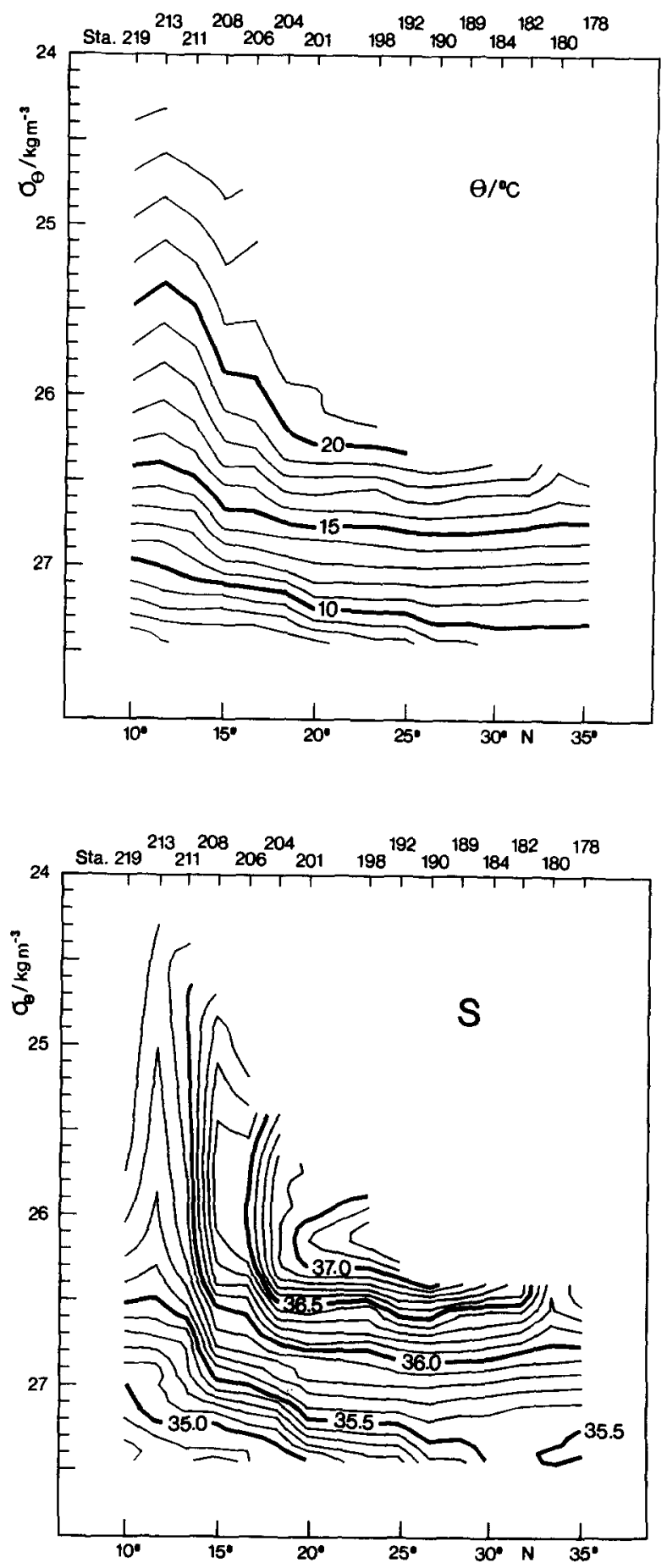

Fig. 8. Sections of potential temperature $\theta$ and salinity $S$ vs potential density $\sigma_{\theta}$ along $27^{\circ} \mathrm{W}$. For station positions see Fig. 4. 


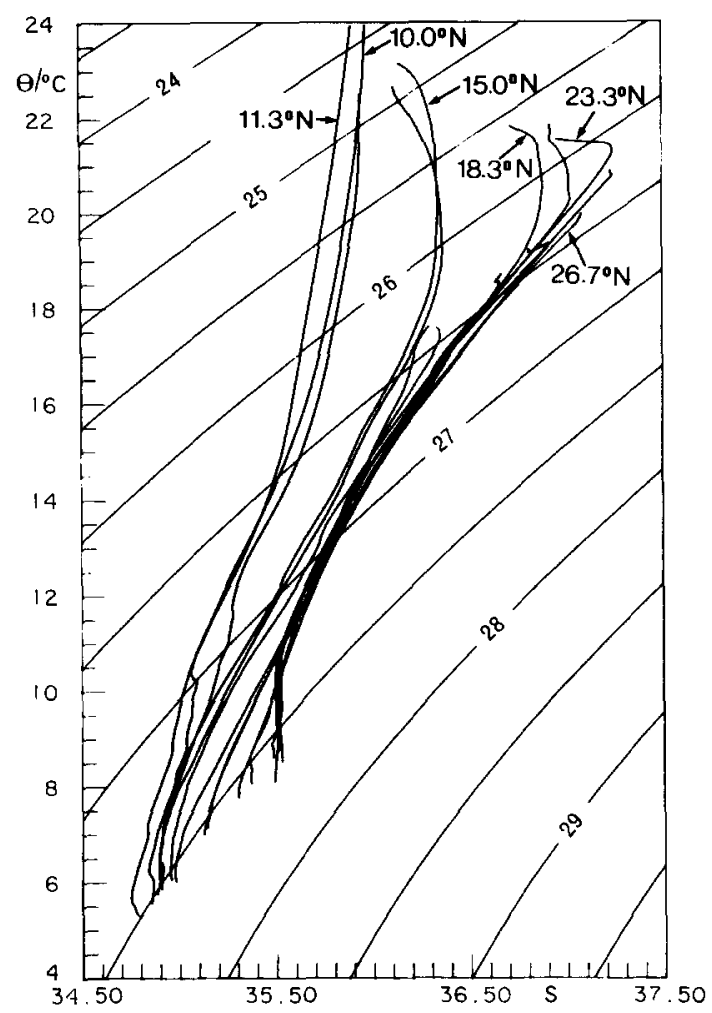

Fig. 9. Potential temperature $(\theta)$-salinity $(S)$ diagram along $27^{\circ} \mathrm{W}$.

south at the lower boundary of the maximum salinity water suggests a downward diapycnal salt flux (TURNER, 1978). Whether this is indeed the case will be discussed later.

Finally a potential temperature/salinity diagram for $27^{\circ} \mathrm{W}$ is presented in Fig. 9. Three features should be noted: (1) Two groups of curves can be distinguished. The two curves on the left represent South Atlantic Central Water, the other curves North Atlantic Central Water. (2) The salinity maximum water is documented in the upper part by the bending of the the curves to the left. (3) In the main thermocline the curves are not linear as would be expected for turbulent mixing. ScHMTT (1981) noted that a curvature corresponding to constant density ratio $R_{\rho}$ is related to the existence of a double-diffusive flux. Here $R_{\rho}$ is given by $R_{\rho}=\alpha \Delta T / \beta \Delta S$, where $\alpha=-\rho^{-1} \partial \rho / \partial T, \beta=\rho^{-1} \partial \rho / \partial S$ and $\Delta T$, $\Delta S$ are the differences of temperature $T$ and salinity $S$ over some vertical interval, and $\rho$ is density.

\section{THE SALT BALANCE EQUATION}

The salt balance equation will be given in isopycnal coordinates mainly in order to eliminate the internal wave noise. Furthermore, in comparison to a pressure-coordinate system, a better vertical resolution is obtained in the upper thermocline layers of tropical latitudes where the salinity maximum water is found. The coordinates in the isopycnal tangent plane are $x^{*}$, and $y^{*}$, directed to the east and to the north, respectively. The third coordinate $z^{*}$ is upward, in opposite direction to the vertical density gradient. 
The salt balance equation in an isopycnal coordinate system contains temporal variation, isopycnal and diapycnal advection, isopycnal and diapycnal eddy diffusion, and diapycnal double diffusion. The general form valid for the mean salinity $(S)$ distribution is given by

$$
\begin{aligned}
S_{t}+ & u^{*} \frac{\partial S}{\partial x^{*}}+v^{*} \frac{\partial S}{\partial y^{*}}+w^{*} \frac{\partial S}{\partial z^{*}}=\frac{\partial}{\partial x^{*}}\left(K_{\mathrm{i}} \frac{\partial S}{\partial x^{*}}\right) \\
+ & \frac{\partial}{\partial y^{*}}\left(K_{\mathrm{i}} \frac{\partial S}{\partial y^{*}}\right)+\frac{\partial}{\partial z^{*}}\left(K_{\mathrm{d}} \frac{\partial S}{\partial z^{*}}\right)-F_{z^{*}}^{s}
\end{aligned}
$$

where $u^{*}$ and $v^{*}$ are the isopycnal velocities positive to the east and to the north, and $w^{*}$ is the diapycnal velocity positive in the upward direction. $K_{\mathrm{i}}$ is the isopycnal and $K_{\mathrm{d}}$ the diapycnal eddy-diffusion coefficient. The eddy diffusion is parameterized following the Fick diffusion law. The diffusion of the mean property field is assumed to act in a downgradient direction, from high to low values, and the eddy-diffusion coefficients are positive. The flux intensity is linearly dependent on the local mean property gradients. The turbulent mixing of heat and salt have the same rate and are parameterized by the same diffusion coefficients. The diapycnal salt flux due to double diffusion is denoted by $F^{s}$, positive in the upward direction. This flux can not be parameterized by an eddydiffusion coefficient because of the different buoyancy fluxes of heat and salt. Furthermore, the double-diffusive salt flux has a non-linear dependence on the salinity difference at the interfaces. The subscripts $t, x^{*}, y^{*}$ and $z^{*}$ will stand for the differentiation with respect to time and space.

To calculate the terms of the salt balance equation, the model of McDougALL (1984) is applied. He has derived a salt conservation equation implicitly containing the diapycnal velocity by substituting for the diapycnal velocity in the salt balance equation using a term derived from the corresponding heat balance equation. Neglecting the diapycnal velocity could lead to considerable errors in the salt balance. Furthermore, he introduced neutral surfaces which are locally defined by the triplets of potential temperature $\theta$, salinity $S$ and pressure $p$. A plane in space is given by the equation

$$
\frac{1}{\rho} \nabla_{j} \rho=\beta \nabla_{j} S-\alpha \nabla_{j} \theta+\kappa \nabla_{j} \rho,
$$

where $\nabla_{j}$ is the two-dimensional gradient operator in the local isopycnal plane. The coefficients, $\alpha, \beta$ and $\kappa$ are the thermal expansion $\alpha=-\rho^{-1} \partial \rho / \partial T$, the haline contraction $\beta=\rho^{-1} \partial \rho / \partial S$ and the compressibility coefficient $\kappa=\rho^{-1} \partial \rho / \partial p$, respectively, which are all functions of $\theta, S$ and $p$.

The movement of a water parcel along a neutral surface is isentropic. This implies the conservation of $\theta$ and $S$ and leads to the equation

$$
\frac{1}{\rho} \nabla_{j} \rho=\nabla_{j} p
$$

Such a motion is also exactly described by the equation

$$
\alpha \nabla_{j} \theta=\beta \nabla_{j} S
$$


when $\theta$ and $S$ vary along the neutral surface. As derived from equation (3), the neutral surfaces are locally identical with density surfaces. A similar equation can be derived for a water parcel which is slightly displaced from a neutral surface. For a water parcel moving isentropically in the vertical, the buoyancy frequency $N$ is defined by the equation (see GILL, 1982)

$$
N^{2}=g\left(\alpha \theta_{z}-\beta S_{z}\right)
$$

Index $z$ stands for the vertical gradient with $z$ increasing in the upward direction, and $g$ denotes the acceleration due to gravity. If the static stability of the water column is neutral, the buoyancy frequency $N$ is equal to zero. This leads to the following equation:

$$
\alpha \theta_{z}=\beta S_{z} \text {. }
$$

Temporal variations of $\boldsymbol{\theta}$ and $S$ along neutral surfaces while conserving entropy and enthalpy leads to the equation

$$
\alpha \theta_{t}=\beta S_{t}
$$

The resulting form of the salt balance equation after substituting the diapycnal velocity and using equations (4), (5), and (7) is given by

$$
\begin{gathered}
S_{t}+\left(\mathrm{v}-\nabla_{j} K_{\mathrm{i}}\right) \cdot \nabla_{j} S=K_{\mathrm{i}} \nabla_{j}^{2} S+K_{\mathrm{d}} \frac{g}{N^{2}}\left(\theta_{z}\right)^{3} \alpha \frac{\mathrm{d}^{2} S}{\mathrm{~d} \theta^{2}}-F_{z}^{s} \frac{R_{\mathrm{p}}-r}{R_{\mathrm{\rho}}-1} \\
+K_{\mathrm{i}} \frac{g}{N^{2}} S_{z}\left[\frac{\partial \alpha}{\partial \theta} \nabla_{j} \theta \cdot \nabla_{j} \theta+\frac{\partial \alpha}{\partial p} \nabla_{j} p \cdot \nabla_{j} \theta\right] .
\end{gathered}
$$

For more details of the transformation see MCDougaLL (1984). In deriving equation (8), the derivatives of the thermal expansion, the haline contraction and the compressibility coefficient with respect to salinity are neglected. It can be easily shown that the terms multiplied by these derivatives are small compared to the remaining terms of the diffusion equation.

The term $r=\alpha F_{z}^{\theta} / \beta F_{z}^{s}$ is the ratio of the vertical gradients of the buoyancy fluxes due to potential temperature $\left(\alpha F_{z}^{\theta}\right)$ and due to salinity $\left(\beta F_{z}^{s}\right)$ variations. Equation (8) contains all the relevant terms with respect to isopycnal and cross-isopycnal directions which contribute to the salt balance. The diapycnal gradients (with respect to $z^{*}$ ) have been replaced by vertical gradients (with respect to $z$ ). This is a good approximation because the angle between the vertical vector and the vector normal to density surfaces is small (typically $\leqslant 0.005^{\circ}$ ).

The elimination of the diapycnal velocity has affected the form of the diapycnal terms in equation (8). This concerns the diapycnal turbulent mixing which appears to be strongly dependent on the curvature of the $\theta-S$ curve and the vertical temperature gradient. The diapycnal double-diffusive salt flux is multiplied by a factor containing the density ratio $R_{\rho}$ and the parameter $r$. This parameter $r$ is not well known, especially when the buoyancy fluxes due to temperature and salinity vary considerably. In the layer below the subtropical salinity maximum water, however, where the almost constant $\theta-S$ relationship of Central Waters apply, the value $r$ can be approximated by the buoyancy flux ratio $R_{f}=\alpha F^{\theta} / \beta F^{s}$. The ratio of the vertical gradients of the buoyancy fluxes is thus assumed to equal the ratio of the buoyancy fluxes themselves. The buoyancy flux ratio $R_{f}$ 
depends on the density ratio $R_{\mathrm{p}}$ as shown by SCHMITT (1979b) and MCDougall and TAYLOR (1984). Below the subtropical salinity maximum water the values for $R_{\mathrm{\rho}}$ are nearly constant and less than 2 , and the buoyancy flux ratio is therefore estimated to be also constant and set to $R_{f}=0.6$ (SCHMITT, 1979b).

The non-linearity of the equation of state introduces the last two terms in equation (8) which are advection processes in the diapycnal direction. The intensities of these diapycnal fluxes are determined by the rate of isopycnal mixing of water masses with different temperature, but same density. The resulting water mass will have a different density due to the non-linearity of the equation of state. The dependence of the thermal expansion coefficient $\alpha$ on potential temperature $\theta$ is responsible for the cabbeling effect, and the dependence of $\alpha$ on pressure $p$ for the thermobaric effect (McDougall, 1987).

The remaining terms in equation (8) are negligible for the analysis of the mean salt balance in the main thermocline. The variation of salinity with time along a density surface can be ignored. The salinity distribution does not change significantly on mesoscales as can be seen from the different data sets. The mean salinity maximum water is found to be distributed as a coherent tongue. The large-scale eddy-diffusion coefficients are therefore assumed to vary only slightly. The situation might be different in the region of the North Atlantic Counter Current. The isopycnal variation of the isopycnal mixing coefficient $K_{\mathrm{i}}$ is small compared to the isopycnal velocity. Ignoring the term $\nabla_{j} K_{\mathrm{i}} \cdot \nabla_{j} S$ corresponds to the assumption of potential energy being distributed isotropically in the area under consideration. This can be concluded from the distribution of eddy potential energy given by DANTZLER (1977).

The effects resulting from the non-linearity of the equation of state will contribute only about $1 \%$ to the salt balance. This small contribution is estimated by using typical values for the buoyancy frequency, the vertical salinity gradient and the isopycnal gradients of potential temperature in the eastern North Atlantic.

Using the above approximations leads to the following form of the diffusion equation:

$$
u^{*} S_{x^{*}}+v^{*} S_{y^{*}}=K_{\mathrm{i}}\left(S_{x x^{*}}+S_{y y^{*}}\right)+K_{\mathrm{d}} \frac{g}{N^{2}}\left(\theta_{z}\right)^{3} \alpha S_{\theta \theta}-F_{z}^{S} \frac{R_{\mathrm{\rho}}-r}{R_{\mathrm{\rho}}-1}
$$

Since only a relatively small depth range is being considered here, equation (9) is also valid for the calculation of the salt balance along potential density surfaces.

In the following analysis the double-diffusive salt flux caused by the vertically unstable salinity stratification will be estimated. TURNER (1973) obtained the following relation for the diapycnal buoyancy flux of salt across an interface with a salinity difference $\Delta S$ :

$$
\beta F^{s}=C\left(g k_{t}\right)^{1 / 3}(\beta \Delta S)^{4 / 3},
$$

where $k_{t}$ is the molecular diffusion coefficient for heat and the factor $C$ is a function of the density ratio $R_{\rho}$.

SCHмIтT (1979a, 1981) used equation (10) for the calculation of the double-diffusive salt flux in the North Atlantic Central Water. He found that $C\left(R_{\mathrm{\rho}}\right)$ could be fitted as follows:

$$
C=0.05+0.3 R_{\mathrm{p}}^{-3} \text {. }
$$

The diapycnal double-diffusive salt flux thus increases with decreasing density ratio $R_{\mathrm{p}}$. ScHMrTt (1979a) has shown that the growth rate of salt fingers should increase rapidly 
when $R_{\mathrm{p}}$ approaches 1 . It has been demonstrated in laboratory experiments that the convective salt flux actually intensifies when the value for $R_{\rho}$ decreases (e.g. TuRnER, 1967).

\section{DETERMINATION OF ADVECTION AND EDDY MIXING}

In order to determine the terms in equation (9) from observational data, first- and second-order isopycnal derivatives are needed as well as the curvature of the $\theta-S$ relationship. North-south derivatives can be obtained from the meridional Meteor sections. The data coverage of the Meteor data set alone, however, is not sufficient to determine all the derivatives, and additional data are required. East-west derivatives were computed from mean temperature-salinity values within $5^{\circ} \times 5^{\circ}$ squares given by EMERY and DEwAR (1982). The curvature of the $\theta-S$ relationship was obtained from the meridional section data.

The CTD data from the two meridional sections had less than usual accuracy due to technical problems. After elimination of drift effects, precision was estimated to be typically $\delta \theta= \pm 0.02 \mathrm{~K}$ and $\delta S= \pm 0.02-0.04$. Because of the large variations of properties in this upper part of the ocean, even the reduced data quality was sufficient for this study. Data editing also included elimination of spikes and instrumental noise, and the reduction of fine-structure by a $50 \mathrm{dbar}$ running-mean filter. Using visual inspection of neighbouring profiles, a vertical-averaging interval was selected which preserved those structures that were apparently correlated between stations while eliminating smallerscale features. By this procedure, however, the salinity at the depth of the salinity maximum was somewhat reduced.

The mean data of EMERY and DewAR (1982) in $5^{\circ} \times 5^{\circ}$ squares were evaluated by averaging the salinity values along several temperature surfaces, $0.2 \mathrm{~K}$ apart. The standard deviations of mean salinity values were of the order $0.01-0.1$. In the northern part of the area they sometimes were found to be larger than the salinity difference between neighbouring squares. The study was therefore restricted to the region south of $30^{\circ} \mathrm{N}$.

The analysis is based on changes on potential density surfaces which are $0.1 \mathrm{~kg} \mathrm{~m}^{-3}$ apart in the depth range between the lower boundary of the surface mixed layer and the surface $\sigma_{\theta}=26.8 \mathrm{~kg} \mathrm{~m}^{-3}$. At tropical latitudes the upper boundary is given by $\sigma_{\theta}=26.2 \mathrm{~kg} \mathrm{~m}^{-3}$, increasing to $\sigma_{\theta}=26.4 \mathrm{~kg} \mathrm{~m}^{-3}$ at subtropical latitudes.

Isopycnal salinity gradients of first and second order were determined by using a spline procedure with a polynomial fit of third order for $S(x)$ and $S(y)$. The standard deviation of the fit varies between $\mathrm{d} S=0.02$ and 0.04 . A remaining systematic error due to the drift in sensor calibration may be responsible for additional errors in isopycnal gradients. The meridional distribution $S(y)$ is seen in Fig. 10. The salinity increases from the south, reaches a maximum at subtropical latitudes, and slightly decreases further to the north. The salinity gradient reverses from positive to negative values; the second derivative is usually negative, except for some perturbations. The corresponding zonal salinity distributions for $27.5,22.5,17.5$ and $12.5^{\circ} \mathrm{N}$ (Figs 11 and 12) show considerable scatter and the gradients are smaller than those in the meridional direction.

The term $\mathrm{d}^{2} S / \mathrm{d} \theta^{2}$ was determined by averaging the vertical profiles from the meridional sections in $0.05 \mathrm{~K}$ temperature intervals. The resulting $S(\theta)$ curves again were splinefitted. For the salinity maximum $d^{2} S / d \theta^{2}$ is negative, and positive values are obtained for 

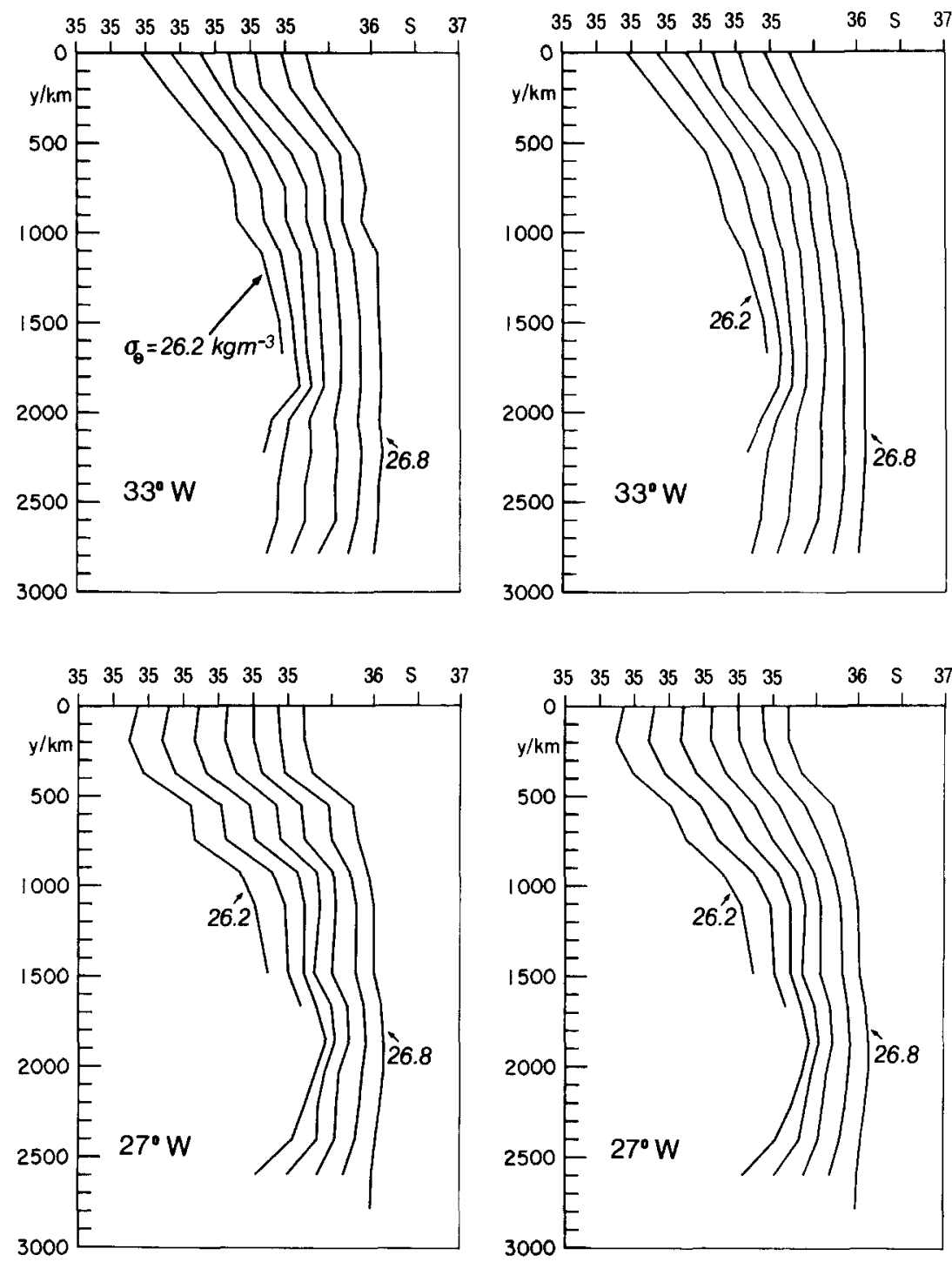

Fig. 10. Meridional changes of salinity $S$ on isopycnal surfaces along $33^{\circ} \mathrm{W}$ (above) and $27^{\circ} \mathrm{W}$ (below) starting from $10^{\circ} \mathrm{N}(y=0)$ to $35^{\circ} \mathrm{N}$. Linearly interpolated original data are presented on the left, spline-fitted data on the right. Curves are shifted by $\Delta S=0.4$ as indicated by the tick marks.

the Central Water. At subtropical latitudes in the source region, the term is positive in the entire depth range investigated here. Further south the vertical salinity maximum covers an increasing density range, and so do the negative values of $\mathrm{d}^{2} S / \mathrm{d} \theta^{2}$. Below the salinity maximum, $\mathrm{d}^{2} S / \mathrm{d} \theta^{2}$ is small, and a turning point with sign reversal cannot be determined exactly. This has to be kept in mind when later discussing the sign of the diapycnal mixing term. That term is also strongly influenced by the vertical gradients of potential temperature that were calculated by a linear regression over $6 \mathrm{dbar}$ intervals. 

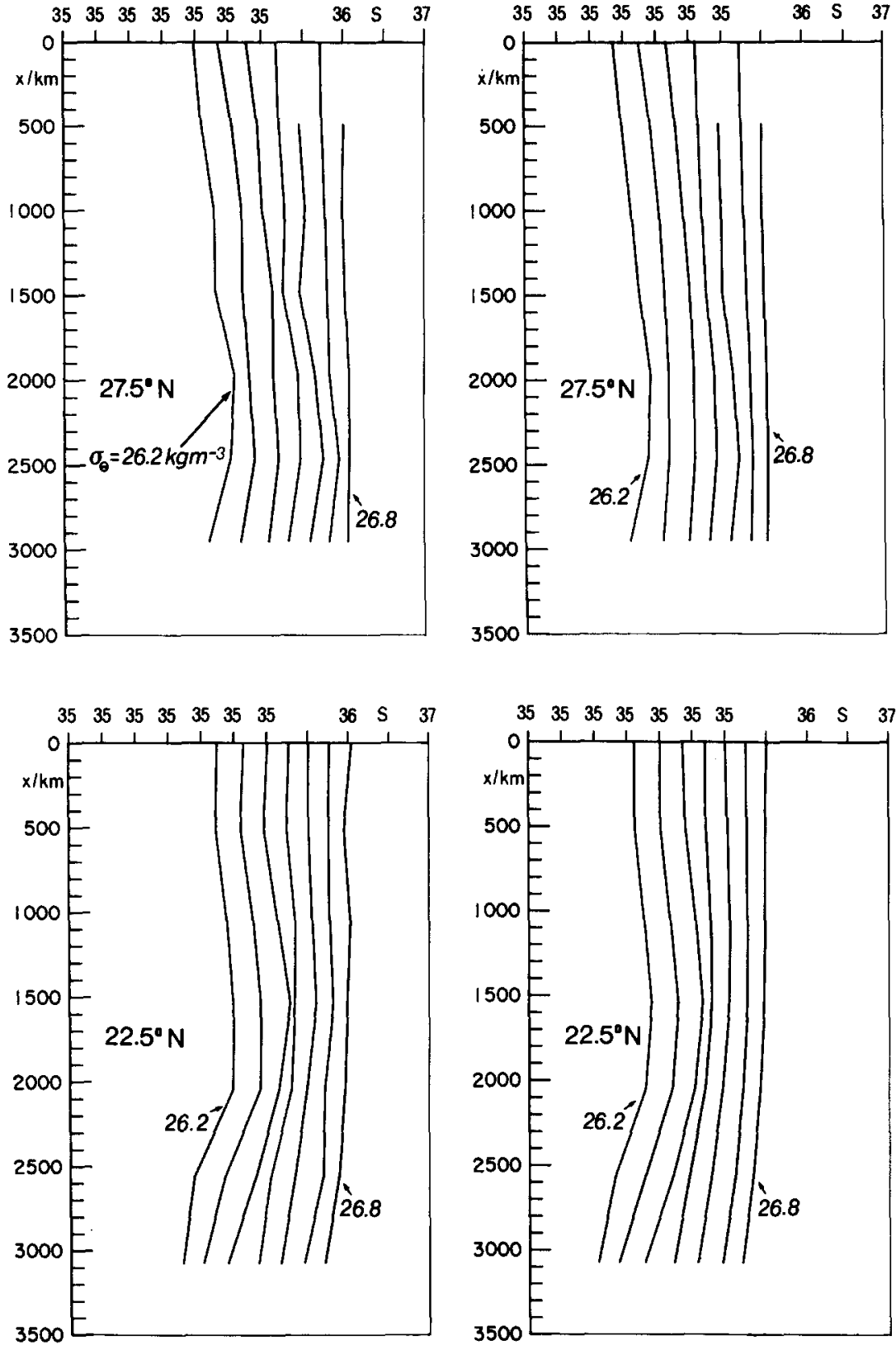

Fig. 11. Zonal changes of salinity $S$ on isopycnal surfaces along $27.5^{\circ} \mathrm{N}$ (above) and $22.5^{\circ} \mathrm{N}$ (below) starting from $47.5^{\circ} \mathrm{W}(x=0)$ to the eastern Atlantic coast. Linearly interpolated original data are presented on the left, spline-fitted data on the right. Curves are shifted by $\Delta S=0.4$ as indicated by the tick marks. 

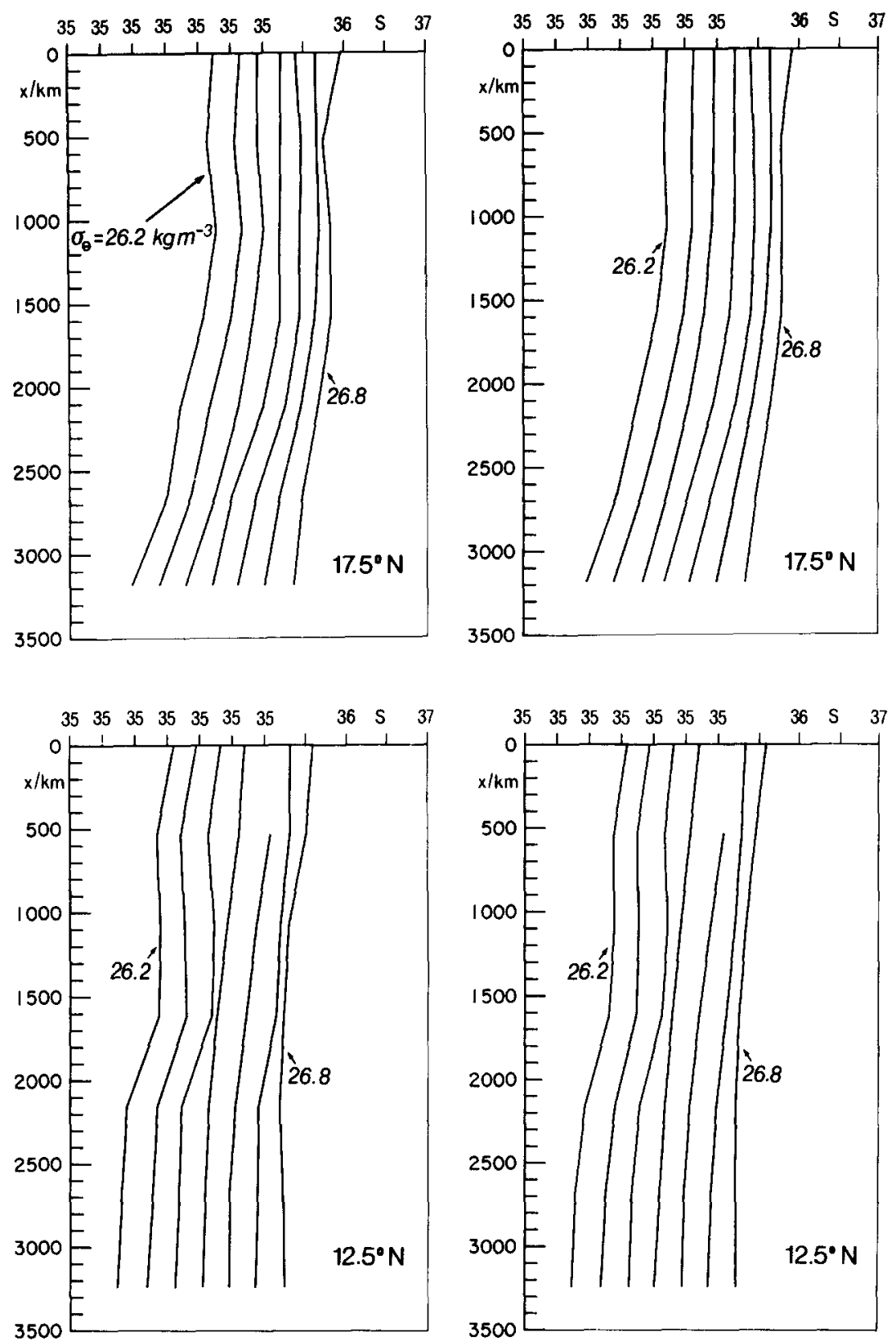

Fig. 12. Zonal changes of salinity $S$ on isopycnal surfaces along $17.5^{\circ} \mathrm{N}$ (above) and $12.5^{\circ} \mathrm{N}$ (below) starting from $47.5^{\circ} \mathrm{W}(x=0)$ to the eastern Atlantic coast. Linearly interpolated original data are presented on the left, spline-fitted data on the right. Curves are shifted by $\Delta S=0.4$ as indicated by tick marks. 


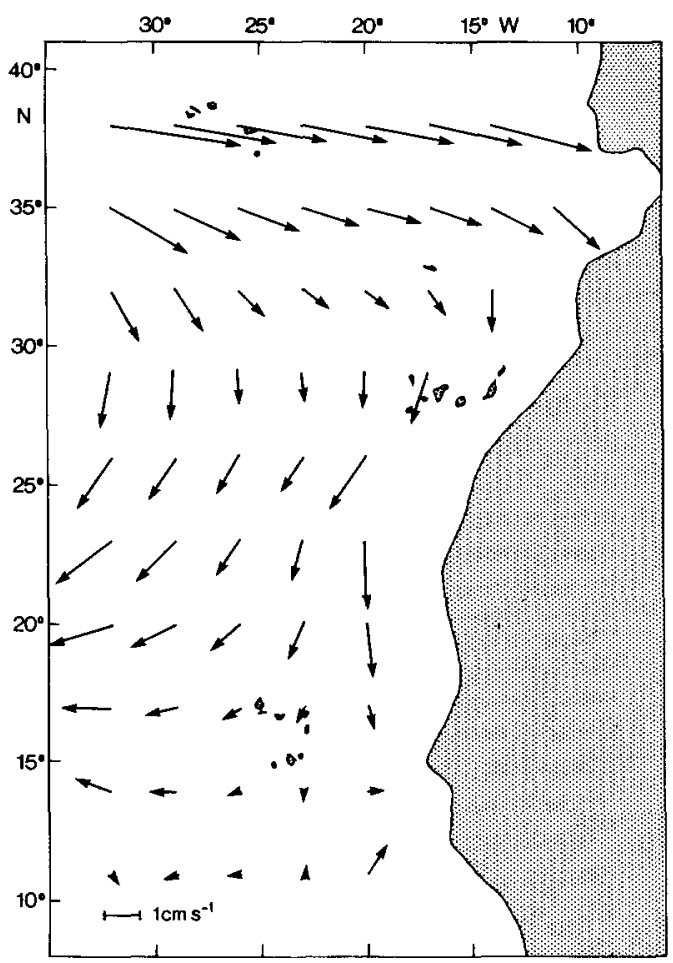

Fig. 13. Velocities on $\sigma_{\theta}=26.5 \mathrm{~kg} \mathrm{~m}^{-3}$ after THIELE et al. (1986).

Since the thermocline steepens towards the south, an increasing contribution can be expected from the diapycnal eddy-mixing term.

Advection velocities were obtained from THIELE et al. (1986). Their study was based on geostrophic current calculations using a historical hydrographic data set and specific determinations of a layer of no motion. Typical relative errors can amount to as much as $30-50 \%$. Zonal velocity components deduced from the quasi-synoptic Meteor meridional sections were slightly higher than the corresponding values from the smoothed historical data set. In order to obtain a consistent flow field, only isopycnal advection velocities from the historical data analysis are used here. An example is shown in Fig. 13.

\section{DOUBLE-DIFFUSIVE SALT FLUX}

The double-diffusive salt flux has been estimated using equations (10) and (11). Due to the noise in the CTD data it was not possible to separate mean and fluctuating fields correctly for a direct determination of the flux. Because of the limited horizontal resolution of the CTD sections it also was impossible to estimate diapycnal salt fluxes induced by isopycnal salinity gradients. The cross-gradient tilt of the plane of the salty water tongue observed can be interpreted as a signal of double-diffusive interleaving (e.g. PoSMENTIER and HibBard, 1982) with up-gradient fluxes at interleaving structures to be expected. In the following discussion this effect is ignored, and only the down-gradient 
salt flux below the interleaving structures will be estimated which is caused by the vertically unstable salinity stratification.

Below the salinity maximum the conditions are favourable for double-diffusive saltfingering, as can be inferred from low values for the density ratio $R_{\rho}$. This ratio has been calculated in the layer bounded by the vertical salinity maximum and the density level $\sigma_{\theta}=26.8 \mathrm{~kg} \mathrm{~m}^{-3}$ over depth intervals of $6 \mathrm{dbar}$. Figure 14 shows the frequency distribution of $R_{\mathrm{\rho}}$ as a function of latitude along $27^{\circ} \mathrm{W}$. It may be regarded as typical because smoothing of the data hardly produces a change in the frequency distribution. At subtropical latitudes the mean values for $R_{\rho}$ are between 1.6 and 1.8 and increase towards the north as well as towards the south. Compared with the mean value of $R_{\mathrm{\rho}}=1.95$, which Schmiтt (1981) determined for the North Atlantic Central Water, the mean density ratio $R_{\mathrm{p}}$ calculated here is slightly smaller.

Low values for the density ratio $R_{\mathrm{\rho}}$ infer that the destabilizing salinity stratification is weakly compensated by the stable temperature stratification and provide indirect evidence for salt-finger activity. The salt-fingering process occurs across interfaces. Layers and interfaces form on microscales, and the process will become intermittent when, for example, the salt supply runs out. Schmitr and Evans (1978) inferred an intermittency factor depending on the occurrence of step-structures. Since below the subtropical salinity maximum water the density ratio $R_{\rho}$ is less than 2 , the salt-fingering process can be assumed to be active and hardly intermittent. As pointed out by MCDougall and TAYLOR (1984), equation (10) may need some modification when being applied to ocean data. Although the 4/3-power law for the salt flux is probably still a good approximation. These limitations in using equation (10) have to be kept in mind for the following discussion.

The buoyancy flux caused by the salt flux $F^{s}$ due to salt-fingering has been computed using equation (10) which probably gives an upper bound of the salt flux. The salinity difference $\Delta S$ was taken over $\Delta p=3 \mathrm{dbar}$ intervals. Tests indicated that the selection of such an interval provided a reasonable compromise between the requirements of good resolution and low noise level. By this choice $\Delta p$ was selected in a way which also ensures the correspondence of the calculated maximum double-diffusive flux $F_{\max }^{s}$ to the mean

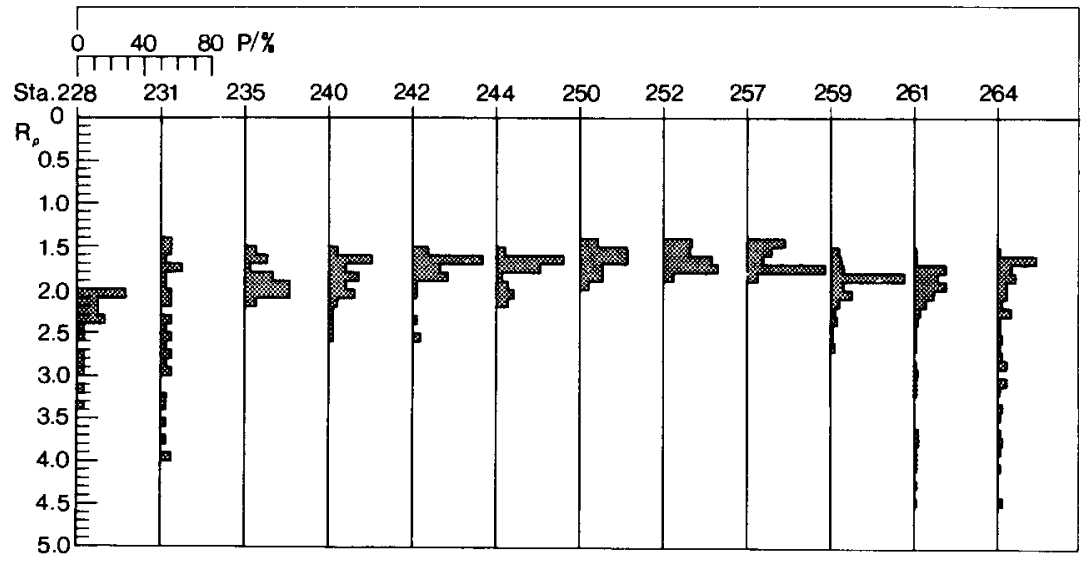

Fig. 14. Frequency distribution $P$ of density ratio $R_{\mathrm{\rho}}$ as a function of latitude along $27^{\circ} \mathrm{W}$ (for station positions see Fig. 4). 
salt flux $F_{e}^{s}$ at the sea surface in the central subtropics. $F_{e}^{s}=1.8 \times 10^{-7} \mathrm{~g} \mathrm{~cm}^{-2} \mathrm{~s}^{-1}$ was obtained from $F_{e}^{s}=S_{0} \rho V$, with salinity $S_{0}=35 \times 10^{-3}$, density $\rho=1 \mathrm{~g} \mathrm{~cm}^{-3}$ and the net evaporation minus precipitation $V=160 \mathrm{~cm} \mathrm{y}^{-1}$ (BAUMGARTNer and ReICHEL, 1975). The order of magnitude of this value is also consisent with $F_{\max }^{s}=2.9 \times 10^{-7} \mathrm{~g}$ $\mathrm{cm}^{-2} \mathrm{~s}^{-1}$ determined by LAMBERT and StuRGEs (1977) in the Central Water of the Caribbean Sea.

As expected, the resulting double-diffusive salt flux (Fig. 15) is maximal at subtropical latitudes and reaches values of the order of the salt flux induced by the net evaporation minus precipitation at the sea surface (LAMBERT and STURGES, 1977; SCHMITT and EvANS, 1978). The density range affected by the double-diffusive salt flux increases to the south, whereas the intensity decreases.

Station $192\left(25^{\circ} \mathrm{N}, 27^{\circ} \mathrm{W}\right)$ is chosen to present an example of the diapycnal salt flux as a function of depth and potential density (Fig. 16). The resulting vertical divergence of the salt flux as a function of potential density is also presented. To reduce the variability of the flux divergence term a linear regression over $30 \mathrm{dbar}$ intervals has been carried out.
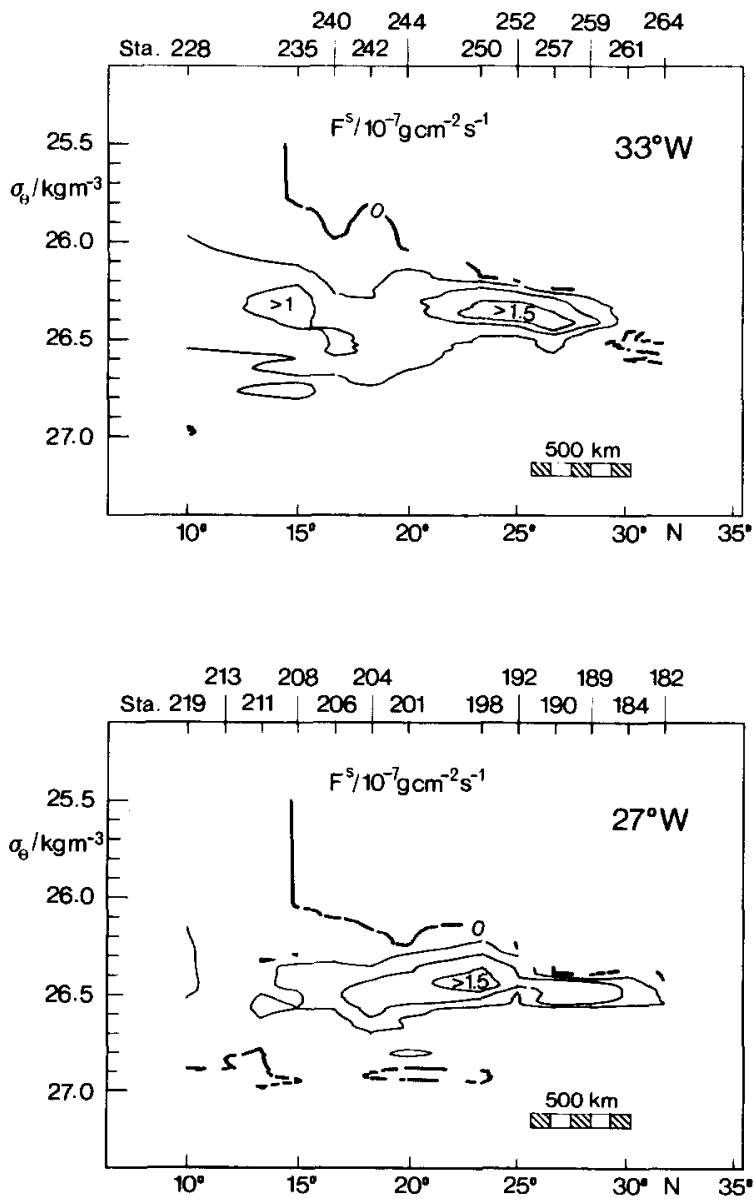

Fig. 15. Meridional sections of the double-diffusive salt flux $F^{s}$ vs potential density $\sigma_{\theta}$ along $33^{\circ}$ and $27^{\circ} \mathrm{W}$ (interval of isolines: $0.5 \times 10^{-7} \mathrm{~g} \mathrm{~cm}^{-2} \mathrm{~s}^{-1}$ ). 

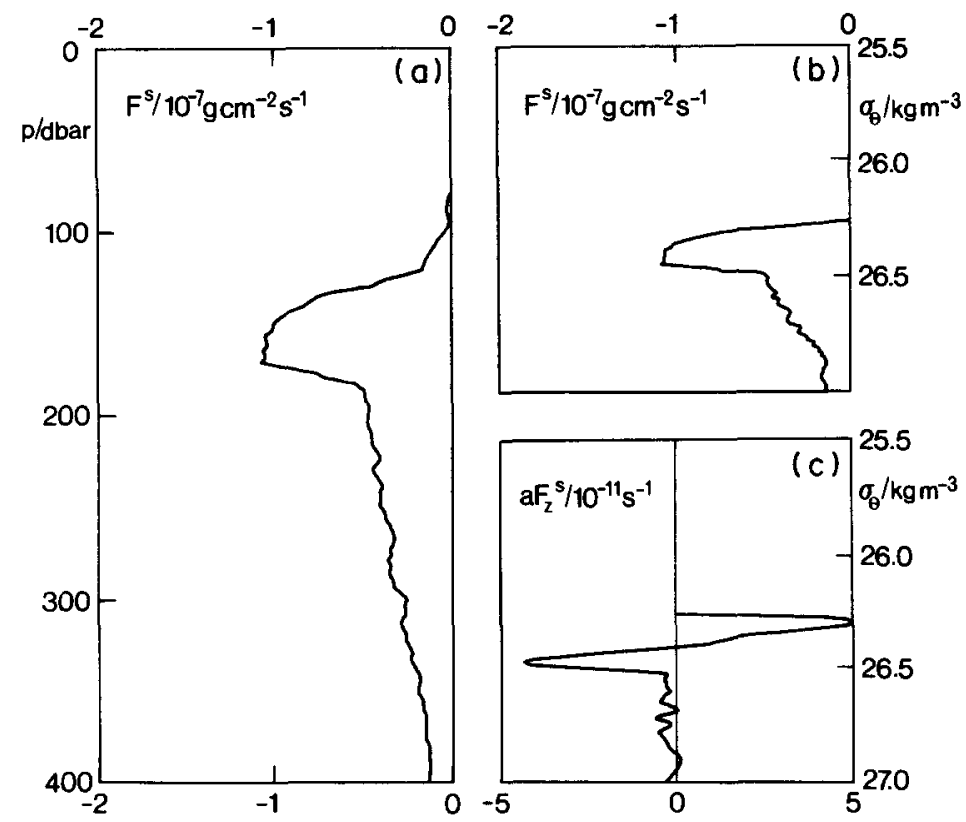

Fig. 16. Station $192\left(25^{\circ} \mathrm{N}, 27^{\circ} \mathrm{W}\right)$ : double-diffusive salt flux $F^{s}$ vs pressure $p(a)$ and vs potential density $\sigma_{\theta}(\mathrm{b})$ and double-diffusive flux divergence $a F_{z}^{s}$ vs $\sigma_{\theta}(\mathrm{c})$ where $a=\left(R_{\mathrm{\rho}}-r\right)\left(R_{\mathrm{p}}-1\right)^{-1}$.

The rapid change of the salt flux with depth induces a strong convergence and also a divergence.

\section{ISOPYCNAL AND DIAPYCNAL EDDY-DIFFUSION COEFFICIENTS}

The remaining unknown eddy-diffusion parameters in the salt balance equation (9) have been estimated using an inverse method. The values of the parameters are found by minimizing the norm of the vector $(\mathrm{A} \cdot \mathbf{X}-\mathrm{b})$, where $A$ is the coefficient matrix, $\mathbf{X}$ the unknown two-dimensional vector representing $K_{\mathrm{i}}$ and $K_{\mathrm{d}}$ and the vector $\mathrm{b}$ denoting the inhomogeneous side. If different vectors give sufficiently small residuals in the linear problem, the case with smallest length can be selected to increase the likelihood of validity of the linear problem (LAwson and HANsON, 1974). Rewriting the salt balance equation leads to the form

$$
\sum_{l=1}^{L}\left(a_{l 1} x_{1}+a_{l 2} x_{2}-b_{l}\right)^{2}=\min ,
$$

where $x_{1}$ stands for $K_{\mathrm{i}}$ and $x_{2}$ for $K_{\mathrm{d}}, a_{11}$ denotes the coefficient of the isopycnal mixing term, $a_{l}$ the coefficient of the diapycnal mixing term, and the vector $b$ consists of the sum of the advection and the divergence of the double-diffusive salt flux. The index $l$ denotes the numbering of equations, and the total number is $L$. Various sources of uncertainty have been determined and the obviously poorly conditioned balance equations disregarded. Ninety equations were found to be applicable for a least-squares fit in the latitudinal range of $15^{\circ}-30^{\circ} \mathrm{N}$ and in the potential density range of $\sigma_{\theta}=26.2-26.8 \mathrm{~kg} \mathrm{~m}^{-3}$. 
Parameterization following the Fick diffusion law requires positive eddy-mixing coefficients. Assuming constant values of the isopycnal and the diapycnal eddy-diffusion coefficients for the whole area, we obtain $K_{\mathrm{i}} \sim 1.1 \times 10^{3} \mathrm{~m}^{2} \mathrm{~s}^{-1}$ and $K_{\mathrm{d}} \sim 4.3 \times 10^{-5}$ $\mathrm{m}^{2} \mathrm{~s}^{-1}$. The standard deviations considering the total data set are clearly smaller than the coefficients themselves. A measure of the least-squares fit is given by $Q S=\Sigma_{j} r_{j}^{2} / \Sigma_{j} b_{j}^{2}$, where $r_{j}$ is the residual of the fitted equation number $j$, and $b_{j}$ is the initial value of the inhomogeneous side. Small values of $Q S$ correspond to well-conditioned equations. The results are listed in Table 1 , also including further case studies.

The total set of equations has been divided into two classes, a western part, consisting of the stations along $33^{\circ} \mathrm{W}$, and an eastern part, taking the stations along $27^{\circ} \mathrm{W}$ in order to check for zonal variations. Secondly, data were separated into a northern and a southern part, with the purpose of identifying differences between the source and the spreading region. The source region is given by stations with the salinity maximum at the sea surface. The spreading region contains the adjacent stations further to the south.

The least-squares method leads to very small diapycnal mixing coefficients $K_{\mathrm{d}}$ in the western and the northern subarea with large standard deviations, and significantly larger isopycnal mixing coefficients $K_{\mathrm{i}}$, compared to the coefficients for the whole area. A good quality of the fits is found in the eastern and southern subarea. Coefficients for the eastern and the southern subarea resemble those for the whole area.

There also may be variations in the eddy-diffusion coefficients due to changes in the advective-diffusive balance. Assuming that the advection velocity and the isopycnal salinity gradients were underestimated, the least-squares fit calculation was repeated, using an advection term increased by $100 \%$. The results are shown in Table 2 . The fitting procedure applied to the total set of equations leads to eddy-mixing coefficients both of which increase by a factor of 2 (compare Tables 1 and 2). Again the diapycnal mixing coefficient $K_{\mathrm{d}}$ is negligibly small in the western and the northern subarea. The overall

Table 1. Isopycnal eddy-mixing coefficients $\mathrm{K}_{i}$ and diapycnal eddy-mixing coefficients $\mathrm{K}_{d}$ including standard deviations derived for the mean hydrographic state by a linear inversion technique for the total region and for four subregions. QS is a measure of the quality of the least-squares fit (see text)

\begin{tabular}{lcrrr}
\hline Case & $\begin{array}{c}\text { Number } \\
\text { of equations }\end{array}$ & \multicolumn{1}{c}{$\begin{array}{c}K_{\mathrm{i}} \\
\left(\mathrm{m}^{2} \mathrm{~s}^{-1}\right)\end{array}$} & \multicolumn{1}{c}{$\begin{array}{c}K_{\mathrm{d}} \\
\left(\mathrm{m}^{2} \mathrm{~s}^{-1}\right)\end{array}$} & $Q S$ \\
\hline Total set & 90 & $(11 \pm 5) \times 10^{2}$ & $(4 \pm 2) \times 10^{-5}$ & 0.87 \\
$33^{\circ} \mathrm{W}$ & 40 & $(42 \pm 17) \times 10^{2}$ & $(0 \pm 9) \times 10^{-5}$ & 0.69 \\
$27^{\circ} \mathrm{W}$ & 50 & $(8 \pm 4) \times 10^{2}$ & $(5 \pm 1) \times 10^{-5}$ & 0.63 \\
Northern set & 30 & $(26 \pm 22) \times 10^{2}$ & $(0 \pm 30) \times 10^{-5}$ & 0.85 \\
Southern set & 46 & $(9 \pm 5) \times 10^{2}$ & $(4 \pm 2) \times 10^{-5}$ & 0.79 \\
\hline
\end{tabular}

Table 2. Isopycnal eddy-mixing coefficients $\mathrm{K}_{i}$ and diapycnal eddy-mixing coefficients $\mathrm{K}_{d}$ including standard deviations derived for the case study of enhanced advection. QS is a measure of the quality of the least-squares fit (see text)

\begin{tabular}{lcccc}
\hline Case & $\begin{array}{c}\text { Number } \\
\text { of equations }\end{array}$ & $\begin{array}{c}K_{\mathrm{i}} \\
\left(\mathrm{m}^{2} \mathrm{~s}^{-1}\right)\end{array}$ & $\begin{array}{c}K_{\mathrm{d}} \\
\left(\mathrm{m}^{2} \mathrm{~s}^{-1}\right)\end{array}$ & $Q S$ \\
\hline Total set & 90 & $(20 \pm 7) \times 10^{2}$ & $(11 \pm 3) \times 10^{-5}$ & 0.74 \\
$33^{\circ} \mathrm{W}$ & 40 & $(45 \pm 21) \times 10^{2}$ & $(0 \pm 11) \times 10^{-5}$ & 0.75 \\
$27^{\circ} \mathrm{W}$ & 50 & $(11 \pm 6) \times 10^{2}$ & $(10 \pm 2) \times 10^{-5}$ & 0.52 \\
Northern set & 30 & $(43 \pm 24) \times 10^{2}$ & $(0 \pm 29) \times 10^{-5}$ & 0.73 \\
Southern set & 46 & $(13 \pm 7) \times 10^{2}$ & $(9 \pm 3) \times 10^{-5}$ & 0.65 \\
\hline
\end{tabular}


Table 3. Isopycnal eddy-mixing coefficients $\mathrm{K}_{i}$ and diapycnal eddy-mixing coefficients $\mathrm{K}_{d}$ including standard deviations derived for the case study ignoring the contribution of doublediffusive salt flux. QS is a measure of the quality of the least-squares fit (see text)

\begin{tabular}{lcccr}
\hline Case & $\begin{array}{c}\text { Number } \\
\text { of equations }\end{array}$ & $\begin{array}{c}K_{\mathbf{i}} \\
\left(\mathrm{m}^{2} \mathrm{~s}^{-1}\right)\end{array}$ & $\begin{array}{c}K_{\mathrm{d}} \\
\left(\mathrm{m}^{2} \mathrm{~s}^{-1}\right)\end{array}$ & $Q S$ \\
\hline Total set & 90 & $(5 \pm 2) \times 10^{2}$ & $(5 \pm 1) \times 10^{-5}$ & 0.56 \\
$33^{\circ} \mathrm{W}$ & 40 & $(9 \pm 4) \times 10^{2}$ & $(0 \pm 2) \times 10^{-5}$ & 0.74 \\
$27^{\circ} \mathrm{W}$ & 50 & $(4 \pm 3) \times 10^{2}$ & $(5 \pm 1) \times 10^{-5}$ & 0.46 \\
Northern set & 30 & $(5 \pm 3) \times 10^{2}$ & $(1 \pm 4) \times 10^{-5}$ & 0.79 \\
Southern set & 46 & $(5 \pm 3) \times 10^{2}$ & $(5 \pm 1) \times 10^{-5}$ & 0.54 \\
\hline
\end{tabular}

quality of the least-squares fits increases slightly, supporting the assumption that the advection term had been underestimated.

A third sensitivity test has been carried out ignoring the double-diffusive salt flux term completely in the initial set of equations. Again the same subdivisions have been chosen. The enhanced quality of these fits (Table 3 ) is presumably due to the missing scatter which the flux divergence term introduced before. Compared to Table 1 , the isopycnal eddy-mixing coefficient is reduced to one half whereas the diapycnal coefficient has hardly changed. In general, the neglect of the double-diffusive salt flux leads to a decrease of the isopycnal eddy-mixing coefficient and to a slight increase of the diapycnal eddy-mixing coefficient. It may be concluded that the contribution of the double-diffusive salt flux is mainly balanced by isopycnal mixing.

The order of magnitude of the eddy-diffusion coefficients given in Table 1 is consistent with results of other studies. They correspond to values for the eastern North Atlantic given by Olbers et al. (1985) who applied the $\beta$-spiral method. They found the isopycnal diffusion coefficient to be in the range (1-5) $\times 10^{2} \mathrm{~m}^{2} \mathrm{~s}^{-1}$ and the diapycnal diffusion coefficient in the range (1-5) $\times 10^{-5} \mathrm{~m}^{2} \mathrm{~s}^{-1}$. ARMI and STOMMEL (1983) determined the isopycnal mixing coefficient to be $K_{\mathrm{i}}=5 \times 10^{2} \mathrm{~m}^{2} \mathrm{~s}^{-1}$ while neglecting the diapycnal mixing completely. THIELE et al. (1985) also neglected diapycnal mixing in their model, arriving at an isopycnal diffusion coefficient of $K_{\mathrm{i}}=17 \times 10^{2} \mathrm{~m}^{2} \mathrm{~s}^{-1}$ south of $30.5^{\circ} \mathrm{N}$ and $K_{\mathrm{i}}=29 \times 10^{2} \mathrm{~m}^{2} \mathrm{~s}^{-1}$ north of $30.5 \mathrm{~N}$.

\section{RELATIVE CONTRIBUTIONS TO THE SALT BALANCE}

By inserting the turbulent diffusion coefficients into the salt balance equation and applying it to a specific region, the relative contributions of the various terms can be determined. Two typical examples for the local salt balance are presented from the section along $27^{\circ} \mathrm{W}$. The first position refers to the source region, and the second to the spreading region. Due to a reduced small-scale variance in the parameter distributions the least-squares fit using the CTD data of the section along $27^{\circ} \mathrm{W}$ yielded slightly better results than the section along $33^{\circ} \mathrm{W}$. The distributions for Sta. $192\left(25^{\circ} \mathrm{N}\right)$ at the potential density level $\sigma_{\theta}=26.4 \mathrm{~kg} \mathrm{~m}^{-3}$ and for Sta. $206\left(16.7^{\circ} \mathrm{N}\right)$ at $\sigma_{\theta}=26.5 \mathrm{~kg} \mathrm{~m}^{-3}$ appear to be particularly good. The relative contributions for these cases are presented in Fig. 17, including the error bars that were obtained by an error propagation analysis. The error estimation is composed of a mean error in the advection velocity, an error in the isopycnal salinity gradients due to the standard deviation of the linear regression, an error for the vertical gradients of temperature and salinity according to the diapycnal 

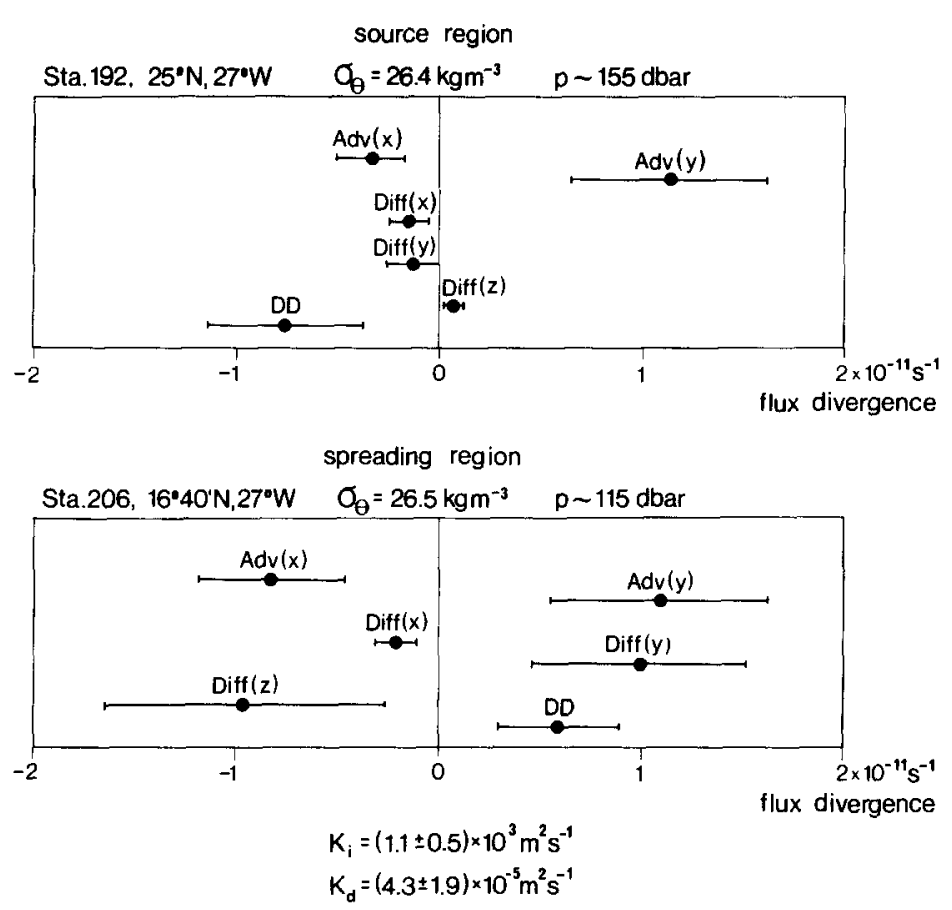

Fig. 17. Magnitudes and errors of the terms in equation (9) for Sta. 192 in the source region and Sta. 206 in the spreading region. Adv. = advection term for $x$ (east) or $y$ (north) direction, Diff $=$ eddy-diffusion term for $x, y$, or $z$ direction, $\mathrm{DD}=$ double-diffusion term.

diffusion term and the error determined for the eddy-mixing coefficients. The calculation of the double-diffusive salt flux is necessarily only approximate since the double-diffusive process is active on small scales, and only the indications for double-diffusive activity on larger scales could be used for the present calculation.

In the source region, the advection velocity is directed towards the southwest, yielding negative values for the two velocity components. The zonal salinity gradients for Sta. 192 are found by linear interpolation of the salinity distributions along $22.5^{\circ}$ and $27.5^{\circ} \mathrm{N}$. Station 192 is located at about $x=2000 \mathrm{~km}$. On the potential density surface $\sigma_{\theta}=26.4 \mathrm{~kg} \mathrm{~m}^{-3}$ the zonal salinity gradient is found to be negative (Fig. 11). The meridional salinity gradient is positive, which can be seen in Fig. 10 at about $y=1660 \mathrm{~km}$. This results in opposite signs for the two components of the advection term. The $y$-component is larger mainly due to a stronger meridional salinity gradient. The contribution of isopycnal diffusion to the salt balance is small because the isopycnal salinity gradients of second order are small. At subtropical latitudes the salinity gradient changes only slightly with distance. In the centre of the subtropical anticyclone the salinity tends to reach a maximum on isopycnal surfaces in the main thermocline, and this corresponds to the negative values of the second derivatives of salinity. Diapycnal mixing is found to be negligibly small. This results from the only slightly curved $S(\theta)$ function and the low vertical gradient of potential temperature at subtropical latitudes. The divergence of the double-diffusive salt flux corresponds to a loss in the balance equation (Fig. 17). The contribution of the double-diffusion term exceeds the 
eddy-diffusion term at this density level and is balanced mainly by advection. At the density level below, however, the diapycnal double-diffusive salt flux is found to decrease and to be balanced predominately by isopycnal mixing.

In the spreading region, the advection velocity at Sta. 206 on the potential density level $\sigma_{\theta}=26.5 \mathrm{~kg} \mathrm{~m}^{-3}$ is also directed to the southwest, whereas the isopycnal salinity gradient is directed to the northwest, towards the central subtropical North Atlantic. The sum of the advection terms represents a relatively small contribution to the salt balance equation, because of the opposing signs of the two components. The two components of the isopycnal eddy-diffusion term have opposing signs, too. The $x$-component has a smaller value than the $y$-component. The reason becomes obvious by inspecting the isopycnal salinity distributions in Figs 10 and 12 . The salinity gradient in the $x$-direction is negative, and the same is true for the second derivative as can be seen at about $x=2100 \mathrm{~km}$ in Fig. 12 . The meridional salinity gradient is positive, and at $y=750 \mathrm{~km}$ a significant increase of the gradient gives a positive and relatively large value for the second derivative of salinity (Fig. 10). The sign of the diapycnal eddy-diffusion term results from the negative curvature of the $S(\theta)$-line, expressed by $\mathrm{d}^{2} S / \mathrm{d} \theta^{2}$.

The relatively large values for the factor $d^{2} S / d \theta^{2}$ and of the factor $\theta_{z}$, which both determine the diapycnal diffusion term, lead to a considerable contribution of this term to the salt balance equation at this location. The intensity of the double-diffusive salt flux decreases with depth, leading to a negative value of the diapycnal gradient of $F_{z}^{S}$. At the selected density level a salt convergence is induced, with a positive contribution to the salt balance. All contributions to the salt balance are of the same order of magnitude at this location.

\section{CONCLUSIONS}

The spatial distribution of the subtropical salinity maximum appears in the form of an almost uniform tongue in those regions off West Africa where this feature had already been found by earlier authors. However, the present study finds an occurrence of such a salinity maximum in regions devoid of the maximum according to DEFANT (1936) and WorthINGTON (1976), although with less probability. Appropriately averaged and smoothed data sets from the regions with a high frequency of occurrence have been used to determine empirically the terms in McDougall's (1984) salt balance equation for neutral surfaces below the salinity maximum layer. The terms include the isopycnal advection and eddy diffusion, the cross-isopycnal advection and eddy diffusion, and the cross-isopycnal double diffusion due to salt-fingering. It was possible in this study to determine both the isopycnal and diapycnal diffusivities.

The depth range below the subtropical salinity maximum has vertical temperature and salinity gradients that are favourable for double diffusion. The density ratios are in the expected range $\left(1<R_{\mathrm{p}}<3\right)$ and thermohaline staircases are observed. Using McDouGALL's (1984) equation the double-diffusive salt flux is an important component of the overall salt flux, with a maximum at subtropical latitudes. No uniform pattern emerges in the contributions of the various terms to the salt balance for the whole area of this study, but typical distributions are found for the near-source and off-source areas and in different isopycnal layers.

The order of magnitude of the turbulent eddy-diffusion coefficients derived by inverse modelling agrees quite well with the upper main thermocline results from other authors. 
In order to check the relevance of double diffusion for the flux divergence the determination of the eddy-diffusion coefficients has been repeated neglecting the contribution of the double-diffusive flux. The isopycnal mixing term was then halved whereas the diapycnal mixing term increased by about $20 \%$. It can be concluded that ignoring the double diffusion in the upper main thermocline at tropical and subtropical latitudes leads to a considerable over-estimation of the turbulent diapycnal mixing term.

Acknowledgements-The authors appreciated the assistance in data collection and processing by the staff of the Marine Physics Department of the Institut für Meereskunde, Kiel, particularly by H. PETERS. We have also benefitted from discussions with T. J. MCDougall, W. J. EMERY, H. LEACH and J. WILLEBRAND. The study was part of the research program "Warmwassersphäre des Atlantiks" (SFB 133) which is funded by the Deutsche Forschungsgemeinschaft.

\section{REFERENCES}

ARmi L. and H. Stommel (1983) Four views of a portion of the North Atlantic Subtropical Gyre. Journal of Physical Oceanography, 13, 828-857.

BAUMgarTnER A. and E. REICHEL (1975) The world water balance. Elsevier, Amsterdam, $179 \mathrm{pp.}$

DANTZler, H. L. (1977) Potential energy maxima in the tropical and subtropical North Atlantic. Journal of Physical Oceanography, 7, 512-519.

DEFANT A. (1936) Schichtung und Zirkulation des Atlantischen Ozeans. Die Troposphäre. Wissenschaftliche Ergebrisse der Deutschen Atlantischen Expedition auf dem Vermessungs- und Forschungsschiff 'Meteor' 1925-27, Vol. 6, Teil I, Liefg. 3, 289-411.

EMERY W. J. and J. S. DEWAR (1982) Mean temperature-salinity, salinity-depth and temperature-depth curves for the North Atlantic and North Pacific. Pergamon Press, Oxford, 305 pp.

GARGETT A. E. (1984) Vertical eddy diffusivity in the ocean interior. Journal of Marine Research, 42, 359-393.

Gill A. E. (1982) Atmosphere-ocean dynamics. Academic Press, London, 622 pp.

LAMBERT R. B. and W. STURGEs (1977) A thermohaline staircase and vertical mixing in the thermocline. Deep-Sea Research, 24, 211-222.

LAwson Ch. L. and R. J. HANSON (1974) Solving least squares problems. Prentice Hall, Englewood Cliffs, New Jersey, 340 pp.

MCDougall T. J. (1984) The relative roles of diapycnal and isopycnal mixing on subsurface water mass conversion. Journal of Physical Oceanography, 14, 1577-1589.

McDougall T. J. (1987) Thermobaricity, cabbeling, and water mass conversion. Journal of Geophysical Research, 92, 5448-5464.

MCDougall T. J. and J. R. TAYLOR (1984) Flux measurements across a finger interface at low values of the stability ratio. Journal of Marine Research, 42, 1-14.

MONTGOMERY R. B. (1938) Circulation in upper layers of southern North Atlantic deduced with use of isentropic analysis. Papers in Physical Oceanography and Meteorology, 6, $55 \mathrm{pp}$.

Olbers D. J., M. WENZEL and J. Willebrand (1985) The inference of North Atlantic circulation patterns from climatological hydrographic data. Reviews in Geophysics, 23, 313-356.

PETERS H. (1978) A compilation of CTD- and profiling current meter data from GATE 1974. "Meteor" Forschungsergebnisse, Reihe A, No. 20, pp. 49-80.

PosmentIER E. S. and C. B. HIBBARD (1982) The role of tilt in double-diffusive interleaving. Journal of Geophysical Reseach, 87, 518-524.

Schmitr R. W. (1979a) The growth rate of super-critical salt fingers. Deep-Sea Research, 26, $23-40$.

SCHMITT R. W. (1979b) Flux measurements on salt fingers at an interface. Journal of Marine Research, 37 , 419-435.

SCHMITT R. W. (1981) Form of the temperature-salinity relationship in the Central Water: Evidence for double-diffusive mixing. Journal of Physical Oceanography, 11, 1015-1026.

Schmit R. W. and D. L. Evans (1978) An estimate of the vertical mixing due to salt fingers based on observations in the North Atlantic Central Water. Journal of Geophysical Research, 83, 2913-2929.

STRAMmA L. (1984) Geostrophic transport in the Warm Water Sphere of the eastern subtropical North Atlantic. Journal of Marine Research, 42, 537-588.

Thiele G., W. Roether, P. Schlosser, R. Kuntz, G. Siedler and L. STramma (1986) Baroclinic flow and transient-tracer fields in the Canary-Cape-Verde Basin. Journal of Physical Oceanography, 16, 814-826.

Turner J. S. (1967) Salt fingers across a density interface. Deep-Sea Research, 14, 599-611.

TURner J. S. (1973) Buoyancy effects in fluids. University Press, Cambridge, 367 pp. 
TURNER J. S. (1978) Double-diffusive intrusions into a density gradient. Journal of Geophysical Research, 83, 2887-2901.

WILLENBRINK E. (1982) Wassermassenanalyse im tropischen und subtropischen Nordostatlantik. Bericht des Instituts für Meereskunde, Kiel, $96,72 \mathrm{pp}$.

Worthington L. V. (1976) On the North Atlantic circulation, Vol. 6, John Hopkins University Press, Baltimore, $110 \mathrm{pp}$. 